\title{
WestVirginiaUniversity
}

THE RESEARCH REPOSITORY @ WVU

Graduate Theses, Dissertations, and Problem Reports

2003

\section{Model predictive control design for load frequency control problem}

Nedzad Atic

West Virginia University

Follow this and additional works at: https://researchrepository.wvu.edu/etd

\section{Recommended Citation}

Atic, Nedzad, "Model predictive control design for load frequency control problem" (2003). Graduate Theses, Dissertations, and Problem Reports. 1813.

https://researchrepository.wvu.edu/etd/1813

This Thesis is protected by copyright and/or related rights. It has been brought to you by the The Research Repository @ WVU with permission from the rights-holder(s). You are free to use this Thesis in any way that is permitted by the copyright and related rights legislation that applies to your use. For other uses you must obtain permission from the rights-holder(s) directly, unless additional rights are indicated by a Creative Commons license in the record and/ or on the work itself. This Thesis has been accepted for inclusion in WVU Graduate Theses, Dissertations, and Problem Reports collection by an authorized administrator of The Research Repository @ WVU. For more information, please contact researchrepository@mail.wvu.edu. 


\title{
Model Predictive Control Design for Load Frequency Control Problem
}

\author{
by \\ Nedžad Atić \\ Thesis submitted to the \\ College of Engineering and Mineral Resources \\ at West Virginia University \\ in partial fulfillment of the requirements \\ for the degree of \\ Master of Science \\ in \\ Electrical Engineering
}

\author{
Powsiri Klinkhachorn, Ph.D. \\ Asadollah Davari, Ph.D. \\ Ali Feliachi, Ph.D., Chair
}

Lane Department of Computer Science and Electrical Engineering

Morgantown, West Virginia

2003

Keywords:

Automatic generation control, Load frequency control, Model predictive control, Decentralized control, Robust control 


\author{
Abstract \\ Model Predictive Control Design \\ for Load Frequency Control Problem \\ by \\ Nedžad Atić \\ Master of Science in Electrical Engineering \\ West Virginia University \\ Ali Feliachi, Ph.D., Chair
}

Load Frequency Control (LFC) is a mechanism by which power generation and power demand are balanced. The main objective of the LFC is to keep the system frequency at its nominal value and maintain inter-area tie-line power flows at their pre-specified contract values. Recent deregulation of the power market have emerged development of novel control techniques that have to include economic objectives as a part of control decisions, and at the same time ensure compliance with the control performance standards, CPS1 and CPS2, established by the North American Reliability Council (NERC).

Model Predictive Control (MPC) has been widely accepted as a viable control strategy in the process industry. It is a model based control strategy where an optimization procedure is performed in every sampling interval over a prediction horizon, yielding an optimal control action. The optimization criterion, or objective function, is chosen in such a way as to satisfy the controlled system dynamics and constraints, penalize system output deviation from the desired trajectory, and minimize control efforts. Furthermore, a possibility to incorporate economic objectives into the optimization criterion makes the MPC a good candidate for power system control.

The first objective of this thesis is an LFC controller design based on the MPC algorithm. The second objective is implementation of additional control logic to the MPC control algorithm to reduce the unit maneuvering, keeping the area under control in good compliance with NERC's standards CPS1 and CPS2. The proposed control techniques are tested on a multiple area power system model within the MATLAB/Simulink environment. 


\section{Acknowledgements}

I would like to take an opportunity and express my gratitude to my adviser Professor Ali Feliachi for his guidance throughout this work. His help, support, creative ideas and suggestions made it more valuable.

I would also like to thank Professors Powsiri Klinkhachorn and Asadollah Davari for serving on my examining committee.

I would like to acknowledge Azra and Amer Hasanović, my dear cousins, for recommending me to Professor Feliachi and helping me to continue my education.

I would like to extend my appreciation to Amer Hasanović, Dulpichet Rerkpreedapong, Ali Karimi, Kourosh Sedghisigarchi, Amer Al-Hinai, Karl Schoder and Joshua Robinson, my colleagues and dear friends at ERB 219, for a great time during the past two years.

Finally, my deepest gratitude goes to my mother Dževdeta and brother Mirsad for always being there for me, and to my beloved wife Saida who has stood by my side through this all. It is to them this work is dedicated.

Funding for this project was provided by the National Science Foundation under grant ECS-9870041 and a DOE/EPSCoR WV state Implementation Award. 


\section{Contents}

List of Figures $\quad$ vi

List of Tables _ vii

1 Introduction $\quad 1$

2 Literature Survey $\quad 3$

3 Background $\quad \mathbf{8}$

3.1 Load Frequency Control . . . . . . . . . . . . . . . . . . 8

3.2 Dynamic model . . . . . . . . . . . . . . . . . . . . . 10

3.3 Control performance standards CPS1 and CPS2 . . . . . . . . . . . . 12

4 Model Predictive Control $\quad 15$

4.1 Prediction based on a step response . . . . . . . . . . . . . . 18

4.2 Performance index . . . . . . . . . . . . . . . . . . . . 22

4.3 Constraints . . . . . . . . . . . . . . . . . . . . . . 24

4.4 An MPC Algorithm . . . . . . . . . . . . . . . . . 27

5 Model Predictive Load Frequency Control 29

5.1 Test system . . . . . . . . . . . . . . . . . . . . . . . . . . . . 29

5.2 Controller design . . . . . . . . . . . . . . . . . . . . . . . . . . . . . . . . . . . . .

5.3 Simulation results . . . . . . . . . . . . . . . . . . . . . . . . . . . . . . . . . . . .

5.3.1 Random load changes . . . . . . . . . . . . . . . . . 33

5.3 .2 Large load disturbances in all control areas . . . . . . . . . . . . . . . . 33

5.3.3 Loss of a generating unit in Control Area 1 . . . . . . . . . . . . . . 35

5.3.4 Generating Rate Constraint handling . . . . . . . . . . . . . . . . 37

6 NERC compliant Model Predictive LFC $\quad 41$

6.1 Test system . . . . . . . . . . . . . . . . . . . . . . . . 41

6.2 Controller Design . . . . . . . . . . . . . . . . . . . . . . . . . . . . . . . . . . . . . .

6.3 Simulation results . . . . . . . . . . . . . . . . . . 45 
CONTENTS

7 Conclusion $\quad 50$

$\begin{array}{ll}\text { A Publications } & 53\end{array}$

B Simulink models and data files $\quad 55$

$\begin{array}{ll}\text { References } & 66\end{array}$ 


\section{List of Figures}

3.1 Generic LFC scheme . . . . . . . . . . . . . . . . . . . . . . . . . 9 9

3.2 Control area dynamic model . . . . . . . . . . . . . . . . . . 10

4.1 General MPC scheme . . . . . . . . . . . . . . . . . . . . . 16

4.2 Receding horizon concept of MPC . . . . . . . . . . . . . . . . . . 17

4.3 Step response on a unit step . . . . . . . . . . . . . . . . . . . . . . . . . 19

5.1 Three-area test system . . . . . . . . . . . . . . . . . . . . . . . . . 30

5.2 Area 1 step response . . . . . . . . . . . . . . . . . . . . . . . 31

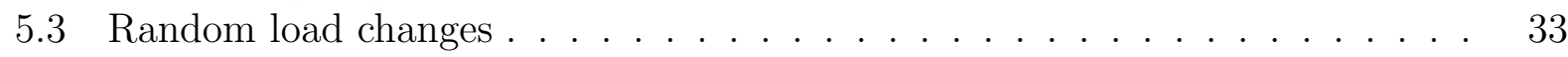

5.4 System response for Scenario 1. MPC - Solid, PI - Dash-dotted . . . . . . . 34

5.5 System response for Scenario 2. MPC - Solid, PI - Dash-dotted . . . . . . . 36

5.6 System response for Scenario 3, first period. MPC - Solid, PI - Dash-dotted . 38

5.7 System response for Scenario 3, second period. MPC - Solid, PI - Dash-dotted 39

5.8 System response for Scenario 4. MPC - Solid, PI - Dash-dotted . . . . . . . 40

6.1 Three-area test system . . . . . . . . . . . . . . . . . . . . . . 42

6.2 Generating unit and prime mover model . . . . . . . . . . . . . . . . 43

6.3 Sliding 12-month time line for $C F_{a c} \ldots \ldots \ldots \ldots$. . . . . . . . . 44

6.4 Aggregate load changes . . . . . . . . . . . . . . . . . . . . 46

6.5 Raise/Lower signals of each generating unit . . . . . . . . . . . . . . 47

$6.6 C P S 1$ compliance . . . . . . . . . . . . . . . . . . . . . . . . . . . . . . . . 48

6.710 -minute average of $\mathrm{ACE}-A V G_{10}[A C E] \ldots \ldots \ldots \ldots$

$6.8 L 1$ norm for all three areas . . . . . . . . . . . . . . . . . . . . . . . . . . 48

B.1 MATLAB/Simulin model for MPLFC . . . . . . . . . . . . . . . . . 55

B.2 MATLAB/Simulin model for NERC compliant MPLFC . . . . . . . . . . . 59 


\section{List of Tables}

5.1 Parameters of generating units . . . . . . . . . . . . . . . . . . . . . . . . . . . . .

5.2 PI Gains . . . . . . . . . . . . . . . . . . . . . . . . . 32

6.1 Load Following Contracts . . . . . . . . . . . . . . . . . 42

6.2 Regulation Contracts . . . . . . . . . . . . . . . . . . . . . . . . . . . . . . . 42

6.3 Generating Unit Parameters . . . . . . . . . . . . . . . . . . . . . . . . 44

6.4 Number of unit reversals . . . . . . . . . . . . . . . . . . . . . . . . . . . . . 49 


\section{Chapter 1}

\section{Introduction}

In the past decade, the electrical industry has undergone deregulation and restructuring, when vertically integrated utilities were forced to split into separate independent generation (Genco), transmission (Transco) and distribution (Disco) companies. These companies are now competing in the market environment, making contracts to provide electric energy and ancillary services. In this type of environment, more efficient companies have better chances to secure those contracts and make profit.

Power systems consist of control areas interconnected through high voltage tie-lines. Constant changes in power demand affect the power system frequency, as well as the tieline power exchange between control areas. Load Frequency Control (LFC) is a mechanism by which a balance between power demand and power generation is maintained with main objectives to keep the system frequency at a nominal value $f^{0}(60 \mathrm{~Hz}$ in the US), and maintain net inter-area tie-line power flows at their pre-specified contract values. In addition to the main objectives, the control actions need to be provided in such a way as to ensure area's compliance with the control performance standards set by the North American Electric Reliability Council (NERC).

Distances between control areas are significant, and a decentralized architecture for LFC is considered in order to reduce the size of monitored network and avoid costs associated with the data communication links. Area Control Error (ACE), a combination of both frequency deviation $(\Delta f)$ and tie-line power exchange deviation $\left(\Delta P_{t i e}\right)$, indicates the power mismatch between the area load and generation. The ACE signal is available at the area control 
centers, and it is used as an input to the LFC controller, thus achieving decentralization.

Because of their relatively simple construction and robust performance, conventional LFC uses proportional-integral (PI) type of controllers. The parameters (gains) of the PI controllers are often obtained through extensive field testing, usually using a trial-and-error approach. Several gain tuning techniques have been proposed, either requiring measurements of all local states which is impractical for industrial applications, or simplifying the problem by assuming that all areas are identical. Additionally, PI controllers could yield unsatisfactory performance since the effects of nonlinearities, such as generation rate constraint and governor dead band were not considered.

In order to operate the system in an efficient manner and to comply with the new market and technical rules, novel control strategies have to be investigated and implemented. Model Predictive Control (MPC) is a control algorithm based on a system model, where an optimization procedure is performed in every sampling interval calculating an optimal control action. During the last decade, the MPC has been proved as a useful control strategy in process industry. It is especially functional since it can handle constraints on control as well as system states and/or output variables. Ability to incorporate economic objectives as a part of control requirements makes it an excellent candidate for the LFC scheme.

The thesis is organized as follows. Literature survey is given in Chapter 2. A basic background on the LFC problem, dynamic model of a control area and an overview of the NERC's control performance standards CPS1 and CPS2 is given in Chapter 3.1. A Model Predictive Control algorithm based on the step response of the system is presented in Chapter 4. A Model Predictive Control design for the Load Frequency Control (MPLFC) is given in Chapter 5. This control technique is successfully tested on a three-area power system model through several case scenarios. Chapter 6 presents the NERC compliant MPLFC control design tested on a power system model, under a scenario that includes load following and regulation service contracts. Finally, concluding remarks are given in Chapter 7 . 


\section{Chapter 2}

\section{Literature Survey}

A literature survey of topics related to Load Frequency Control designs, together with an overview of Model Predictive Control related topics, is given in this chapter.

In an interconnected power system, changes in load without adequate changes in generated power affect the system's frequency as well as inter-area power exchange. Since the load can change at any given time, it is desirable to have an automated balancing mechanism to adjust the power generation. The most preferred method of Automatic Generation Control (AGC) is the tie-line bias control [1]. In the tie-line bias control, Area Control Error (ACE), which is a combination of the tie-line power flow deviation and frequency deviation, is used as an input to the controller. The ACE signal is calculated as:

$$
\begin{gathered}
A C E=[\text { Actual Net Interchange }- \text { Scheduled Net Interchange }]- \\
-[(10 \times \text { Bias }) \times(\text { Actual Frequency }-60 \mathrm{~Hz})]
\end{gathered}
$$

where the first part is the ACE equation for constant net interchange control, and the second part is the ACE equation for constant frequency control. Reviews of the AGC technologies that are utilized by the utilities are given in [2] and [3].

Many control techniques for LFC have been proposed over the years. Centralized control design, where decisions are made based on information acquired from all control areas within an interconnection, is impractical since involves data exchange between distant control areas, which could increase costs of such a system operation. Hence, a decentralized control with decisions that are based on locally available information is more appropriate for the LFC problem. 
Feliachi [4] proposes a decentralized control scheme where decentralized control feedback gains are considered in such a way that the eigenvalues of the closed loop decentralized system are the same as the eigenvalues of the system under the centralized optimal control law. The gains for the decentralized controller are calculated through an iterative procedure from eigenvalue sensitivity expressions already computed based on the centralized case, and they are updated when a disturbance occur. The initial values for the gains, together with the eigenvalue sensitivity vectors, are obtained from the solution of an off-line centralized optimal control problem.

For better interconnected power system operation, Jaleeli et al. [5] proposed wedge control philosophy where an off-zero ACE is tolerated to some extent. This control philosophy bounds average ACE within a wedge shaped funnel, with the main features that reacts to large changes in demand immediately, but does not see small changes of ACE with its average value limited with the designated funnel over period of time. Several benefits that can be obtained implementing the wedge control philosophy are given in the paper. Some of them are: maintaining acceptable frequency, fast response to large deviations in demand, reduction of interconnection time error and inadvertent accumulation, etc. Unit maneuvering and associated wear and tear can be also reduced since generating respond to changes in ACE only if they exceed the funnel bounds.

PI type controllers have emerged as a standard for LFC applications. This is mainly because of their simple structure and robust performance. However, the controller parameters (gains) are usually tuned based on a trial-and-error procedure, and fixed over a certain period of time. There are several techniques proposed for PI gains tuning, but there is also a need for new control techniques, especially in a deregulated environment where economic objectives have to be considered in control design.

An analysis and design issues in LFC for an interconnected power systems are addressed in [6]. The authors have proposed an integral type controller with the gain adjusted using the Quantitative Feedback Theory (QTF) to ensure stability and robustness over large uncertainties in dynamic models of power systems. An additional phase lead stage is added to the integral type controller in order to reduce the peak resonance and oscillations of the system output on a step load disturbance.

In [7], Rerkpreedapong et al. proposed two robust decentralized control techniques for 
LFC. The first technique implements an $H_{\infty}$ control design using linear matrix inequalities (LMI) technique to obtain robustness against uncertainties. This technique results in a high order dynamic controller that treats the area interconnections and local load as a disturbance. The objective is to design an output feedback control law such that the effects of the disturbance do not exceed a given guaranteed robust performance index. The second technique implements a PI controller whose gains are tuned in such a way that the same robust performance as with the first technique is achieved. The control objective is the same as for the first technique, with an additional constraint that the controller is of a PI type. The design procedure uses genetic algorithm (GA) search technique to find the best PI gains under the robust $H_{\infty}$ constraints in terms of LMIs. This new technique is called the Genetic Algorithms and Linear Matrix Inequalities (GALMI) technique, and it could be very interesting for industry application. However, this technique replaces a complex high order controller with a simple PI based controller, using a heuristic search technique to find the control gains, that heavily depend on the search parameters such as seed, number of populations, etc., so there is no guaranties that the optimal parameter solution will be found.

Rerkpreedapong further proposed several new LFC strategies in his PhD Dissertation [8]. He developed several robust decentralized control strategies with the focus on the PI type of controllers. He also proposed a NERC standards oriented LFC strategy, where the gains of implemented PI controllers are obtained using fuzzy logic and changed "on-line" based on the current compliance with CPS1 and CPS2 [9]. For another control design, the wedge-shaped control criteria is used to adjust the control tightness, and the control gains are determined "on-line" with the spline curve obtained from a set of "off-line" GALMI computed gains for different tightnesses [10]. He also applied a simulation on a fully modeled power system using the Power Analysis Toolbox (PAT) package [11], and showed no observable differences of the LFC performance when the results are compared to the ones obtained with the classical LFC model which is commonly used for simulations and analysis.

Donde at al. [12] proposed an optimization technique for finding an integral feedback gain $K_{I}$ using trajectory sensitivities in conjunction with gradient type Newton algorithm. 
As the algorithm optimization criterion, the integral of square error is chosen:

$$
C=\int_{0}^{\infty}\left[\alpha\left(\Delta P_{\text {tie,error }}\right)^{2}+\beta(\Delta f)^{2}\right] d t
$$

This optimization procedure requires simulations of the system model to be performed in every algorithm iteration which could be time consuming. Moreover, the parameters are calculated only for the certain load scenario, with an assumption that all the areas are identical, which is not the case for real power systems.

On February 1, 1997, the NERC introduced new control performance standards CPS1 and CPS2 in place of existing A1 and A2. Jaleeli and VanSlyck in [13] give a brief description of the new control performance standards with their technical foundation and the research leading to the standards. They have noted then too tight control of ACE is impractical and puts a lot of stress on the generating units, and when reasonably tolerated the suppliers can obtain benefits from an interconnected operation. The authors drew conclusions that the new standards can be applied to all types of areas, that they can provide information on area performance over a longer time interval (12 months), and an opportunity for fuel and unit wear and tear savings. More details on NERC's performance standards are given in Chapter 3.3.

Gross and Lee presented an analytic framework for formulation and evaluation of control performance standards CPS1 and CPS2 in [14]. The authors proposed more general control performance criteria $\mathrm{C} 1$ and $\mathrm{C} 2$, with the existing CPS1 and CPS2 given as a special case of the proposed ones. Moreover, an analysis based on the application of the proposed framework showed that the two NERC's standards are redundant under conditions typically in effect in North American interconnections, and that once CPS1 is satisfied implies satisfaction of CPS2 for window length $W \geq 10$. However, according to the NERC's data [15], some control areas had very good compliance with CPS1 while violating CPS2.

Model predictive control has become very attractive control technique, especially for linear processes, with a rising interest for applications in nonlinear processes. A tutorial overview is given in [16] that gives a framework in which the critical issues can be expressed and points out what should be considered to implement this control strategy. In the last couple of decades, MPC has been implemented in wide variety of industrial applications ranging from chemical to aerospace industries. An overview of industrial MPC techniques 
with more than 2200 applications is given in [17] and [18].

In [19] and [20], authors have considered a distributed MPC scheme where the distributed controllers can exchange information through agents. In this scheme, the agents use information from the neighbor agents to estimate the effects of the neighboring control actions to their own area. Such a control scheme is then tested in a power system application, LFC problem in particular, with only a simple swing equation based model of a two-area power system. Although successful control performance was demonstrated in a case of distributed control, a completely decentralized scheme did not yield stable system control. Moreover, the proposed distributed controllers have agent based modules able to exchange information, and they are assumed to know the load disturbance in their own areas. Additionally, the proposed strategy does not consider the net power interchange error, and assumes the availability of the generator rotor angle measurements, which is not practical for implementation.

A huge interest in novel LFC control designs has increased even more with deregulation of power systems when economic objectives became an important factor in control decisions. This thesis presents a new method for robust decentralized LFC. The objective of this thesis is twofold:

- to propose novel control strategy for the Load Frequency Control technique based on a Model Predictive Control algorithm,

- to develop an MPC control scheme which will ensure good compliance with the NERC's control performance standards CPS1 and CPS2, reducing unit maneuvering and associated costs.

Both control designs are based solely on information available at the area control centers, thus achieving decentralized scheme. The proposed control designs will be tested on two three-area power system models, within the Matlab/Simulink environment. 


\section{Chapter 3}

\section{Background}

This chapter will provide a basic background on the Load Frequency Control problem. Also, a dynamic model of a generic control area with multiple generating units will be presented. Finally, an overview of the NERC's control performance standards CPS1 and CPS2 will be given.

\subsection{Load Frequency Control}

Changes in power system load temporarily create a mismatch between generation and demand affecting the system's frequency. For good power system operation, the system frequency should remain at the nominal value $f^{0}$. Also, in an interconnected power system operation, in addition to the frequency control, the tie-line power interchange between areas should be kept at the scheduled value. The frequency control provided by the load's and governor's natural sensitivity to the frequency change is called the primary frequency control loop. However, the primary control loop rarely restores the balance between generation and demand at the nominal frequency, therefore a supplemental or secondary control loop is needed. Since the load changes are frequent, it is desirable that the secondary frequency control is performed automatically. This control of frequency and generation is called Load Frequency Control (LFC).

It is very difficult to obtain measurements of all the generation and all the load in the system to calculate the mismatch between the generation and obligation in one area. The 


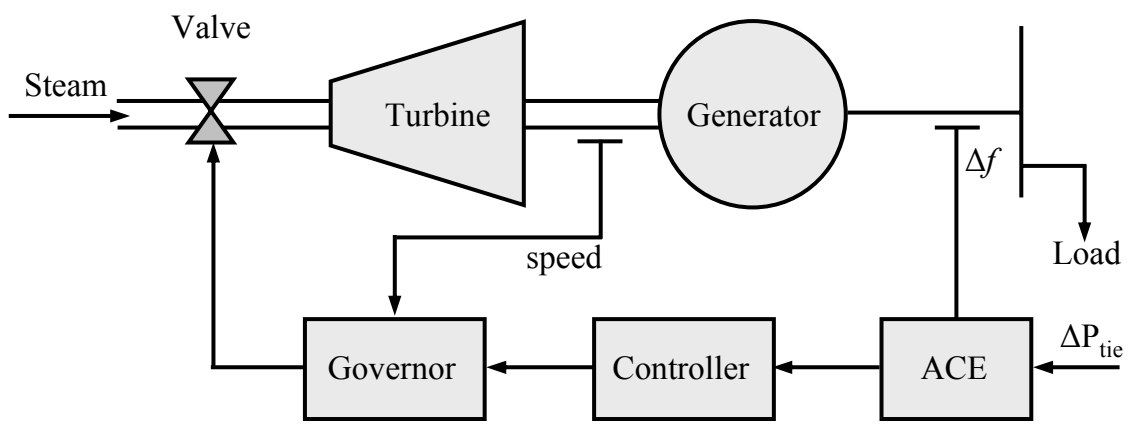

Figure 3.1: Generic LFC scheme

mismatch is measured at the area control center with Area Control Error (ACE) as:

$$
\begin{aligned}
A C E & =P_{t i e}^{a c t}-P_{t i e}^{s}-10 B\left(f^{a c t}-f^{s}\right) \\
& =\Delta P_{t i e}-10 B \Delta f
\end{aligned}
$$

where $P_{\text {tie }}^{a c t}$ and $P_{\text {tie }}^{s}$ are the area's actual and scheduled (manually set) interchange with neighboring areas, $f^{a c t}$ and $f^{s}$ are the area's actual and scheduled frequency, and $B$ is the area's frequency bias coefficient, a negative number measured in $M W$ per $0.1 \mathrm{~Hz}$. Often, the ACE signal is calculated using the area frequency response characteristic $\beta$ instead of $B$ :

$$
A C E=\Delta P_{t i e}+\beta \Delta f
$$

with

$$
\beta=D+\frac{1}{R}
$$

where $D$ is the area's load-damping coefficient, or the frequency sensitivity of the area's load $\left(D=\partial P_{D} /\left.\partial f\right|_{f=f^{0}}\right)$, and $R$ is the regulation due to governor action in the area, or droop characteristic.

Figure 3.1 presents a general overview of the LFC mechanism. Changes in load, create changes in the electrical torque of the generator, and this change results in a mismatch between the mechanical and electrical torque, resulting in speed variations. The governor will sense the change in speed, and adjust the valve position to increase/decrease steam flow from furnace toward turbine in order to balance the torque mismatch (primary loop). This balance is rarely performed at the nominal frequency. Therefore, in order to achieve the nominal frequency of the system and compensate for the power imbalance, the governor's 


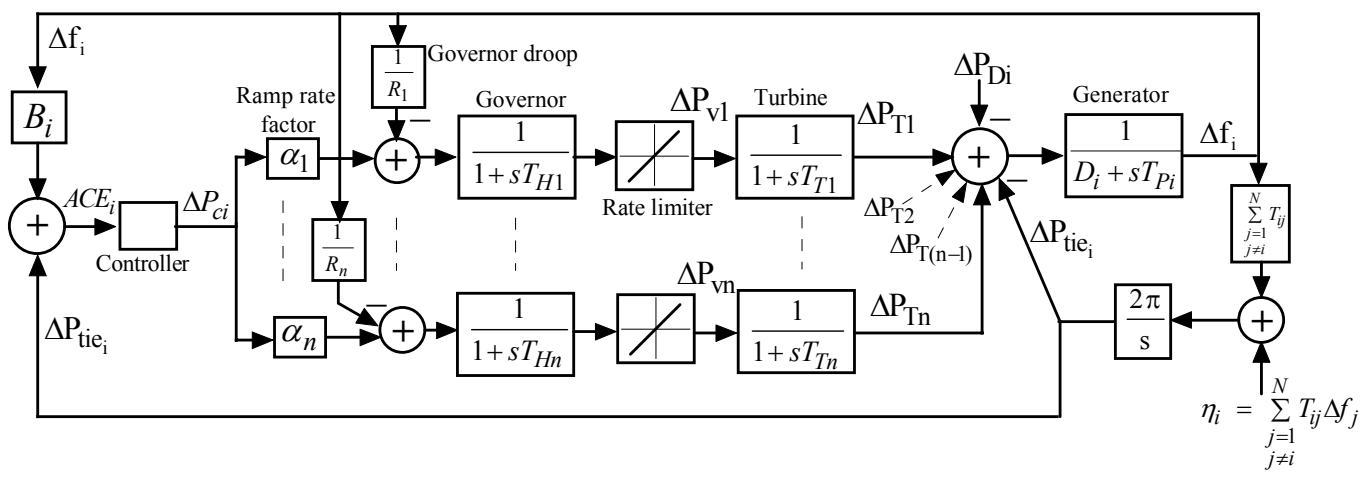

Figure 3.2: Control area dynamic model

setpoint is changed by the actions of an LFC controller whose decisions are based on the ACE signal (secondary loop). These control actions need to be taken in timely manner and have to provide robust power system operation under a number of different contingency situations. Also, a good LFC performance is desirable, and the control areas are obligated to achieve a certain level of quality of power system operation, assessed through the NERC's control performance standards CPS1 and CPS2.

\subsection{Dynamic model}

Figure 3.2 represents a dynamic model of a generic control area, interconnected with other areas through tie lines. To obtain the area frequency deviation $\Delta f$, generators are lumped into one transfer function, and the governors and turbines are modeled with their appropriate transfer functions, where:

$\begin{array}{llll}P_{V} & \text { - governor valve; } & P_{T} & \text { - turbine power; } \\ P_{C} & \text { - governor load setpoint; } & P_{D} & \text { - power demand; } \\ T_{H} & \text { - governor time constant; } & T_{T} & \text { - turbine time constant; } \\ D & \text { - area load damping coefficient; } & T_{P} & \text { - area aggregate inertia; } \\ R & \text { - droop characteristic; } & B & \text { - frequency bias; } \\ f & \text { - area frequency; } & P_{t i e} & \text { - net tie-line flow; } \\ A C E & \text { - area control error; } & \eta & \text { - area interface; } \\ \alpha & \text { - ramp rate factor; } & N & \text { - number of control areas; } \\ \Delta & \text { - deviation from nominal values; } & \\ T_{i j} & \text { - Tie-line synchronizing coefficient between area } i \text { and } j .\end{array}$


By ignoring the nonlinearities in the model, a linearized mathematical model of area $i$ with $n$ generating units can be written [8]:

Governor : $\quad \Delta \dot{P}_{V k}=-\frac{1}{T_{H k}} \Delta P_{V k}+\frac{1}{T_{H k}}\left(-\frac{1}{R_{k}} \Delta f_{i}+\alpha_{k} \Delta P_{C i}\right)$

Turbine : $\quad \Delta \dot{P}_{T k}=-\frac{1}{T_{T k}} \Delta P_{T k}+\frac{1}{T_{T k}} \Delta P_{V k} \quad ; k=1, \ldots, n$

Generator : $\Delta \dot{f}_{i}=-\frac{D_{i}}{T_{P i}} \Delta f_{i}+\frac{1}{T_{P i}}\left(\sum_{l=1}^{n} \Delta P_{T l}-\Delta P_{t i e_{i}}-\Delta P_{D i}\right)$

The tie-line power deviation between area $i$ and area $j$ is defined as:

$$
\Delta P_{i j}=T_{i j}\left(\Delta \delta_{i}-\Delta \delta_{j}\right)
$$

where $\Delta \delta_{i}$ and $\Delta \delta_{j}$ are the phase angle deviations in areas $i$ and $j$. With $\Delta \dot{\delta}_{i}=2 \pi \Delta f_{i}$, a state equation for $\Delta P_{t i e_{i}}$ for area $i$ can be written:

$$
\Delta \dot{P}_{t i e_{i}}=\sum_{\substack{j=1 \\ j \neq i}}^{N} \Delta \dot{P}_{i j}=2 \pi \sum_{\substack{j=1 \\ j \neq i}}^{N} T_{i j}\left(\Delta f_{i}-\Delta f_{j}\right)
$$

Dynamic model of the system as described with equations (3.4) and (3.6) in a state-space form is given with:

$$
\begin{aligned}
& \dot{x}_{i}=A_{i} x_{i}+B_{u i} u_{i}+B_{w i} w_{i} \\
& y_{i}=C_{i} x_{i}
\end{aligned}
$$

where:

$$
\begin{aligned}
& x_{i}=\left[\begin{array}{lllllll}
\Delta f_{i} & \Delta P_{t i e_{i}} & \underbrace{\Delta P_{V 1}}_{n \text { units }} & \Delta P_{T 1} & \ldots & \Delta P_{V n} & \Delta P_{T n}
\end{array}\right]^{T} ; \quad y_{i}=A C E_{i} \\
& u_{i}=\Delta P_{C i} ; \quad w_{i}=\left[\begin{array}{cc}
\eta_{i} & \Delta P_{D i}
\end{array}\right]^{T} ; \quad \eta_{i}=2 \pi \sum_{\substack{j=1 \\
j \neq i}}^{N} T_{i j} \Delta f_{j} \\
& A_{i}=\left[\begin{array}{cc}
A_{11} & A_{12} \\
A_{21} & A_{22}
\end{array}\right] ; \quad B_{u i}=\left[\begin{array}{c}
0_{2 \times 1} \\
B_{u 2}
\end{array}\right] ; \quad B_{w i}=\left[\begin{array}{c}
B_{w 1} \\
0_{2 n \times 2}
\end{array}\right] \\
& A_{11}=\left[\begin{array}{cc}
-\frac{D_{i}}{T_{P i}} & -\frac{1}{T_{P i}} \\
2 \pi \sum_{\substack{j=1 \\
j \neq i}}^{N} T_{i j} & 0
\end{array}\right] ; \quad A_{12}=[\underbrace{\left[\begin{array}{cc}
\frac{1}{T_{P i}} & 0 \\
0 & 0
\end{array}\right] \ldots\left[\begin{array}{cc}
\frac{1}{T_{P i}} & 0 \\
0 & 0
\end{array}\right]}_{n \text { units }}]
\end{aligned}
$$




$$
\begin{aligned}
& A_{21}=\left[\begin{array}{cc}
{\left[\begin{array}{cc}
-\frac{1}{T_{H 1} R_{1}} & 0 \\
0 & 0
\end{array}\right]} \\
\vdots \\
{\left[\begin{array}{cc}
-\frac{1}{T_{H n} R_{n}} & 0 \\
0 & 0
\end{array}\right]}
\end{array}\right] ; A_{22}=\left[\begin{array}{ccc}
{\left[\begin{array}{cc}
-\frac{1}{T_{H 1}} & 0 \\
\frac{1}{T_{T 1}} & -\frac{1}{T_{T 1}}
\end{array}\right]} \\
\\
0_{2 n-2 \times 2 n-2} \\
\left.\quad \begin{array}{cc}
-\frac{1}{T_{H n}} & 0 \\
\frac{1}{T_{T n}} & -\frac{1}{T_{T n}}
\end{array}\right]
\end{array}\right] \\
& B_{u 2}=\left[\begin{array}{c}
{\left[\begin{array}{c}
\frac{\alpha_{1}}{T_{H 1}} \\
0
\end{array}\right]} \\
\vdots \\
{\left[\begin{array}{c}
\frac{\alpha_{n}}{T_{H n}} \\
0
\end{array}\right]}
\end{array}\right] ; \quad B_{w 1}=\left[\begin{array}{cc}
0 & -\frac{1}{T_{p i}} \\
-1 & 0
\end{array}\right] ; \quad C=\left[\begin{array}{lll}
\beta_{i} & 1 & 0 \\
0
\end{array}\right]
\end{aligned}
$$

In the state-space model representation (3.7), $x_{i}$ is the area state vector, $y_{i}$ is the area output vector, $u_{i}$ is the area input $\left(\Delta P_{C i}\right)$, and $w_{i}$ is the area disturbance that includes changes in local load $\Delta P_{D i}$ as well as the area interface $\eta_{i}$.

This linearized dynamic model of a generic control area is developed with simple onestage transfer functions for the key components. If the system components modeled with more details are used, there should be no problem to develop the state-space representation of such a system, with small alteration of the procedure given in this chapter.

\subsection{Control performance standards CPS1 and CPS2}

On February 1, 1997 the North American Electric Reliability Council (NERC) introduced two control performance standards: CPS1 and CPS2 [13], [21]. As of January 1998, control areas are required to be in compliance with the two standards, with penalties for those areas that fail to meet the requirements. A brief introduction to the CPS1 and CPS2 standards is given next.

CPS1 is defined as follows [21]: Over a given period, the average of the clock-minute averages of a control areas [ACE divided by ten times its bias] times the corresponding clock-minute averages of the interconnections frequency error shall be less than the constant 
on the right-hand side of the following inequality:

$$
A C E_{\text {Period }}\left[\left(\frac{A C E_{i}}{-10 B_{i}}\right)_{1} * \Delta F_{1}\right] \leq \epsilon_{1}^{2}
$$

where:

$\left(A C E_{i}\right)_{1}$ - clock-minute average of ACE;

$B_{i} \quad$ - frequency bias of the control area;

$\Delta F_{1} \quad$ - clock-minute average of frequency error;

$\epsilon_{1} \quad$ - targeted frequency bound for CPS1;

Period a) one year for control area evaluation,

b) one month for Resources Subcommittee review.

The CPS1 is calculated as a compliance percentage as follows:

$$
C P S 1=(2-C F) * 100 \%
$$

where $C F$ is a compliance factor:

$$
C F=A V G_{12-m o n t h}\left[C F_{1}\right]
$$

and $C F_{1}$ is a 1-minute average compliance factor:

$$
C F_{1}=\left[\left(\frac{A C E_{i}}{-10 B_{i}}\right)_{1} *\left(\frac{\Delta F}{\epsilon_{1}^{2}}\right)_{1}\right]
$$

CPS2 is defined as follows [21]: Over a clock ten-minute period, the ten-minute averages of a control areas ACE shall be less than the constant on the right-hand side of the following inequality:

$$
A V G_{10-\text { minute }}\left(A C E_{i}\right) \leq L_{10}
$$

where

$$
L_{10}=1.65 \epsilon_{10} \sqrt{\left(-10 B_{i}\right)\left(-10 B_{s}\right)}
$$

and

$\epsilon_{10}$ - targeted frequency bound for CPS2;

$B_{i} \quad$ - frequency bias of the control area;

$B_{s} \quad$ - sum of the frequency bias settings of the control areas in the interconnection.

For the systems with variable bias, CPS2 becomes:

$$
A V G_{10-\text { minute }}\left(A C E_{i}\right) \leq L_{10}
$$


where

$$
L_{10}=1.65 \epsilon_{10}\left[-10 A V G_{10-\text { minute }}\left(B_{i}\right)\right] \sqrt{\frac{B_{s}}{B_{\text {minimum }}}}
$$

and

$B_{\text {minimum }}$ - area's minimum allowed bias.

The CPS2 is calculated as a compliance percentage as follows:

$$
C P S 2=\left[1-\frac{\text { Violations }_{\text {month }}}{\left(\text { Total Periods }_{\text {month }}-\text { Unavailable Periods }_{\text {month }}\right)}\right] * 100 \%
$$

where Violations month are count of the number of periods that $A C E_{10-\text { minute }}$ exceeded $L_{10}$.

Targeted frequency bounds $\epsilon_{1}$ and $\epsilon_{10}$ are based on historical information of the frequency error, and each interconnection is assigned with its own frequency bounds.

After calculating CPS1 and CPS2 using equations (3.9) and (3.16), the control area compliance rating is obtained as:

Control Compliance Rating $=$ Pass $\quad$ - if CPS $1 \geq 100 \% \quad$ and $\quad C P S 2 \geq 90 \%$;

Control Compliance Rating $=$ Fail $\quad$ - if $C P S 1<100 \% \quad$ or $\quad C P S 2<90 \%$

Implementation of CPS1 and CPS2 allows less unit maneuvering and reduces unit wear and tear, while still providing a good basis for a reliable interconnected operation of the power system. 


\section{Chapter 4}

\section{Model Predictive Control}

Model Predictive Control (MPC) has become an effective and accepted control strategy in chemical, oil, automotive, structural and many other industries. It is an open loop control scheme based on a system model, where in a sampling interval the future system behavior is predicted over a finite prediction horizon, and a sequence of future control signals is calculated by minimization of a performance index. Only the first control signal from the sequence is used as the system input, while the rest of the signal sequence is not considered. The whole procedure is repeated in the next sampling interval with the prediction horizon moved one sampling interval forward. The system output is taken into consideration in the optimization procedure through the error between the actual measured output in the current sampling interval and the prediction of the output made in the previous sample. Since the future system behavior is calculated over a shifted prediction horizon, model predictive control is also called receding or moving horizon control.

Model predictive control is a procedure of solving an optimal control problem that includes system dynamics and constraints on the system input and output variables. There is a number of formulations of the MPC strategy that are different either in a way the system model is obtained (i.e. step response model or finite impulse response model), or in a formulation of the objective function. However, they all explicitly use a model of the system to obtain the control signal by minimizing the objective function.

An MPC scheme is presented in Figure 4.1 and the receding horizon concept of model predictive control is illustrated in Figure 4.2. First, an appropriate system model and op- 


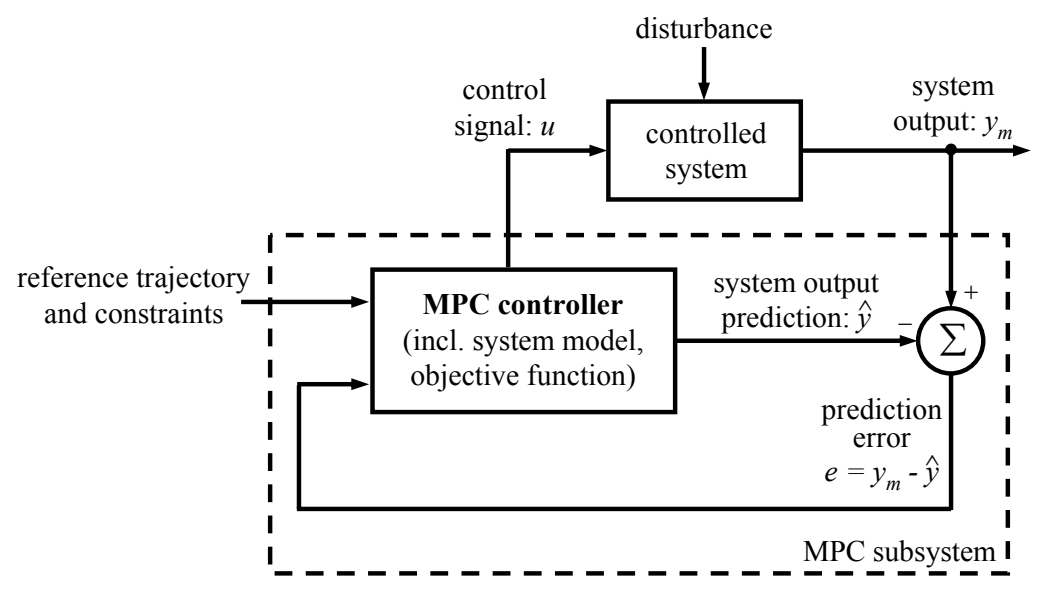

Figure 4.1: General MPC scheme

timization objective are specified. The model will be used to determine the future system responses $\hat{y}(k+1)$, hence it needs to include the dynamics of the system. Then, a desired reference trajectory $y_{r}(k+1)$ and constraints on output and control variables are defined. Prediction of the future system behavior is then made over a prediction horizon, based on the information about past system behavior and the sequence of future control signals that are required to satisfy the optimization objective. The error of the previous step output prediction is calculated as $e(k)=y_{m}(k)-\hat{y}(k)$, where $y_{m}(k)$ is the actual measured output and $\hat{y}(k)$ is the prediction of the output made in the previous sample. This error is taken into account in the optimization procedure. A part of the prediction error accounts for the system model uncertainties, and the other part accounts for the effects of unmeasured disturbance on the system output. The first of the calculated control signals is implemented as the input to the system till the new measurements are available. In the next sampling interval the actual system output $y_{m}(k+1)$ is obtained and the whole procedure is repeated.

The following steps can summarize the core of an MPC algorithm:

1. At the sampling interval $k$ obtain the system measurements $y_{m}(k)$ and calculate the prediction error $e(k)=y_{m}(k)-\hat{y}(k)$.

2. Calculate (predict) the output $\hat{y}(k+i), i=1, \ldots, p$ over the prediction horizon $p$. The prediction is obtained by using the system model, optimizing the objective function with respect to control inputs $u(k+j-1), j=1, \ldots, m$ over the control horizon $m$, 


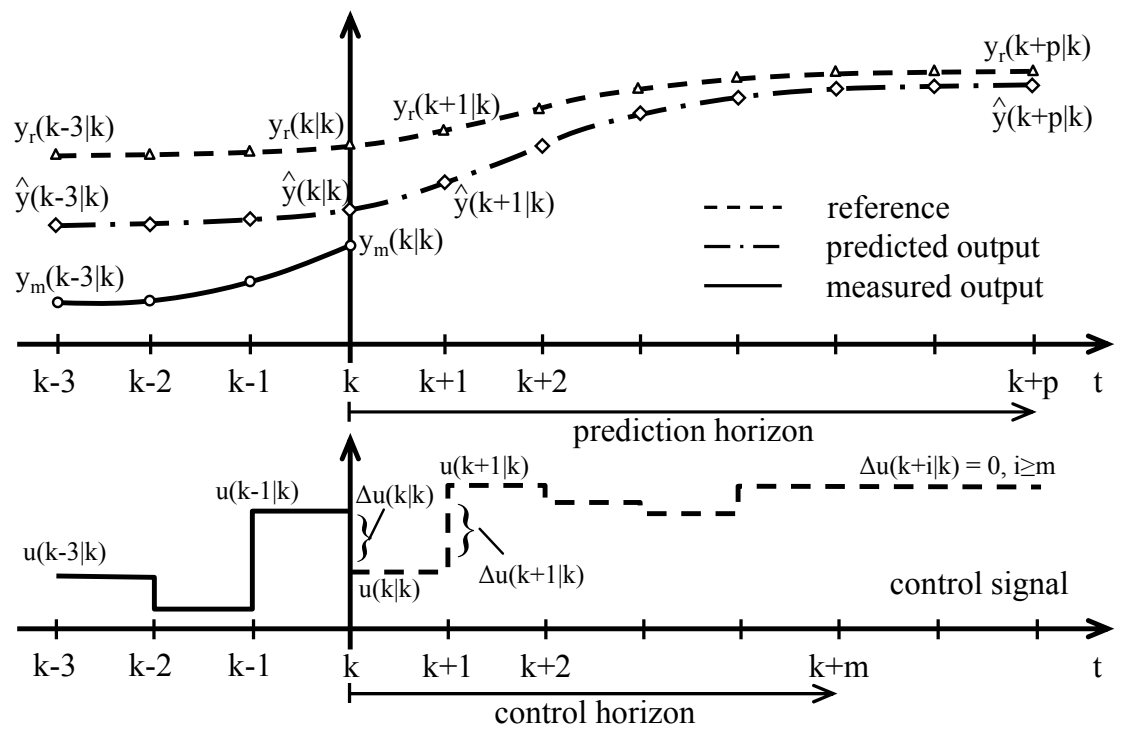

Figure 4.2: Receding horizon concept of MPC

satisfying given constraints. The current state of the system is used as the initial state for the prediction.

3. Apply the first control signal $u(k)$ obtained from the optimization procedure until new measurements are available.

4. At the sampling interval $k+1$ go to step 1 and repeat the procedure.

The prediction and control horizons in the MPC algorithm are essential for good a performance of an MPC controller and they should be chosen carefully to get desired results [22], [23]. The output horizon $p$ should be chosen long enough so it covers the system settling time, making it possible to look further to the more stable behavior. The control horizon $m$ is often smaller number than prediction horizon $p$, and it represents the number of possible control moves. Values of $p$ and $m$ directly influence calculation time required to solve the optimization problem, therefore they should be selected carefully in order to keep computational efforts manageable in real time. The performance index is usually chosen in a quadratic form, penalizing the system output deviation from the reference trajectory and calculating an optimal sequence of control inputs. Minimization of such a performance index can be transformed into a Quadratic Programing (QP) problem and then solved with one of widely available algorithms [24], [25]. It is very important to choose a proper sampling time. 
The sampling interval basically depends on the dynamics of the system under control. Systems with slow response time do not require frequent samplings, although that would yield better control actions. However, short sampling intervals would increase a computational burden in every step, thus making a real-time control impractical.

The following sections will give a mathematical formulation of an MPC algorithm based on a step response system model [23]. The equations are given for a Single Input Single Output (SISO) system, but with small modifications they hold for a Multi Input Multi Output (MIMO) system as well.

\subsection{Prediction based on a step response}

Standard mathematical equations that describe dynamics of a linear time invariant (LTI) system in a state-space domain are:

$$
\begin{aligned}
& \dot{x}(t)=A_{c} \cdot x(t)+B_{c}^{u} \cdot u(t)+B_{c}^{d} \cdot d(t) \\
& y(t)=C \cdot x(t)
\end{aligned}
$$

where $x(t), y(t), u(t)$, and $d(t)$ are vectors of state, output input and disturbance variables respectively, and $A_{c}, B_{c}^{u}, B_{c}^{d}$ and $C$ are the system, input, disturbance and output matrices, with appropriate dimensions. Index $c$ stands for continuous.

The corresponding discrete-time system will be:

$$
\begin{aligned}
& x(k+1)=A_{d} \cdot x(k)+B_{d}^{u} \cdot u(k)+B_{d}^{d} \cdot d(k) \\
& y(k)=C \cdot x(k)
\end{aligned}
$$

where

$$
\begin{aligned}
A_{d} & =e^{A_{c} \cdot \Delta t} \\
B_{d}^{u} & =\int_{0}^{\Delta t} e^{A_{c} \cdot \zeta} d \zeta \cdot B_{c}^{u} \\
B_{d}^{d} & =\int_{0}^{\Delta t} e^{A_{c} \cdot \zeta} d \zeta \cdot B_{c}^{d}
\end{aligned}
$$

where index $d$ stands for discrete.

If a unit step input $u=\left[\begin{array}{llll}1 & 1 & \ldots & 1\end{array}\right]$ is applied to the system (4.2) at rest without considering the effects of disturbance, i.e. $d(k)=0, k=1,2, \ldots$, the output will be the 


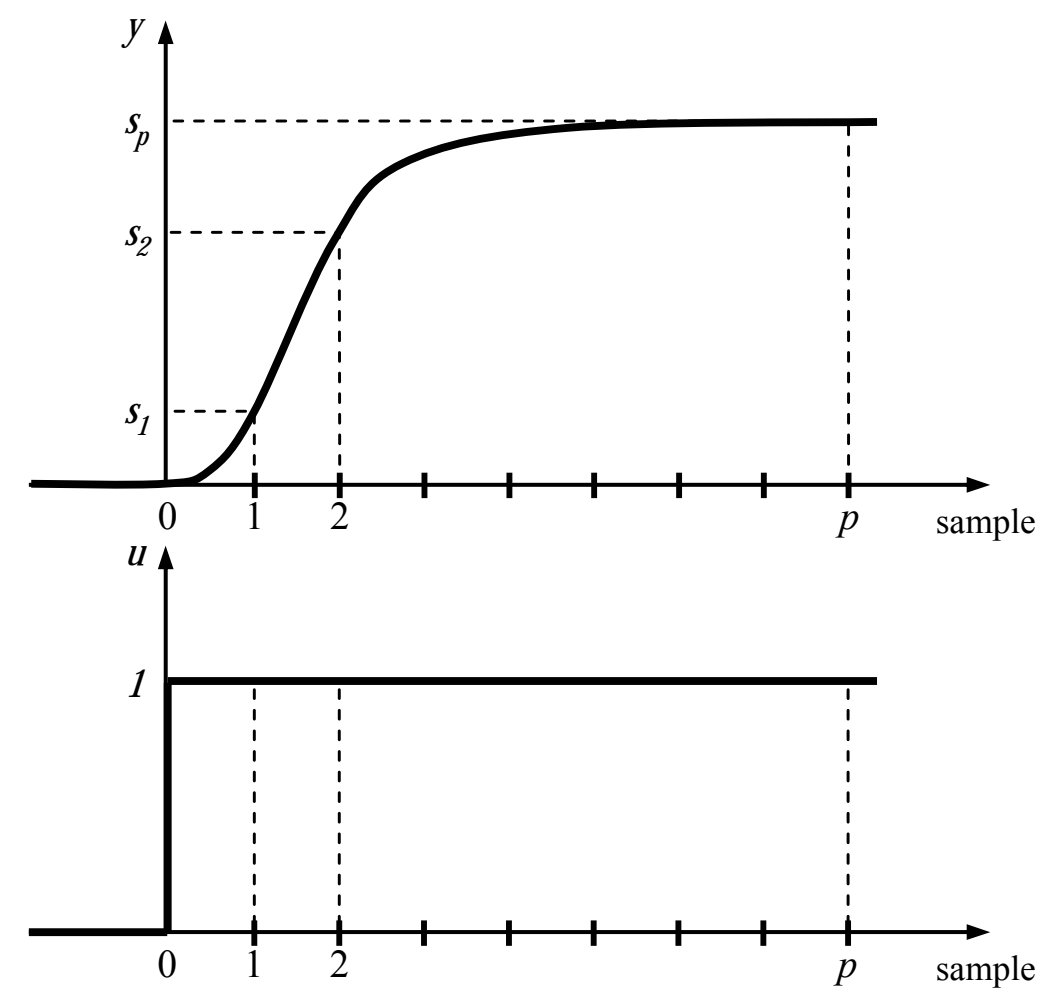

Figure 4.3: Step response on a unit step

step response of the system on the unit step input $y=\left[\begin{array}{lllll}0 & s_{1} & s_{2} & \ldots & s_{p}\end{array}\right]$ with $s_{1}, s_{2}, \ldots, s_{p}$ presenting the step response coefficients at sampling time $k=1,2, \ldots, p$ (Figure 4.3). The step response coefficients can be calculated as:

$$
s_{p}=C \cdot A_{d}^{p} x(0)+\sum_{i=1}^{p} C \cdot A_{d}^{i-1} \cdot B_{d}
$$

and for zero state response as:

$$
s_{p}=\sum_{i=1}^{p} C \cdot A_{d}^{i-1} \cdot B_{d}
$$

For linear systems, a shifted unit step input $u=\left[\begin{array}{lllll}0 & 1 & 1 & \ldots\end{array}\right]$ will produce a shifted step response $y=\left[\begin{array}{llllll}0 & 0 & s_{1} & s_{2} & \ldots & s_{p}\end{array}\right]$, and a scaled step input $u=\left[\begin{array}{llll}u_{l} & u_{l} & \ldots & u_{l}\end{array}\right]$ will produce a scaled step response $y=\left[\begin{array}{lllll}0 & s_{1} u_{l} & s_{2} u_{l} & \ldots & s_{p} u_{l}\end{array}\right]$.

For an arbitrary input $u=\left[\begin{array}{lllll}u_{0} & u_{1} & u_{2} & \ldots & u_{p-1}\end{array}\right]$ applied to the system at rest $\left(y_{0}=0\right)$, the 
output based on the step response coefficients is:

$$
\begin{aligned}
& y_{1}=s_{1} u_{0} \\
& y_{2}=s_{2} u_{0}+s_{1}\left(u_{1}-u_{0}\right) \\
& y_{3}=s_{3} u_{0}+s_{2}\left(u_{1}-u_{0}\right)+s_{1}\left(u_{2}-u_{1}\right)
\end{aligned}
$$

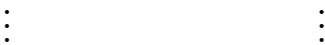

$$
\begin{aligned}
& y_{p}=s_{p} u_{0}+s_{p-1}\left(u_{1}-u_{0}\right)+\ldots+s_{1}\left(u_{p-1}-u_{p-2}\right)
\end{aligned}
$$

Defining $\Delta u_{i}=u_{i}-u_{i-1}, i=1,2, \ldots$, and assuming that the first input was also an input change $\left(u_{0}=\Delta u_{0}\right)$, the output at sampling time $k$ is given with:

$$
y_{k}=\sum_{i=1}^{k} s_{k-i+1} \Delta u_{i-1}
$$

Based on the step response model of the system we can make a prediction of the system output at the sampling time $k$ over the prediction horizon $p$ :

$$
\begin{array}{ccc}
\hat{y}(k+1 \mid k)= & \hat{y}(k+1 \mid k-1)+s_{1} \Delta u(k \mid k)+w(k+1 \mid k) \\
\hat{y}(k+2 \mid k)= & \hat{y}(k+2 \mid k-1)+s_{2} \Delta u(k \mid k)+s_{1} \Delta u(k+1 \mid k)+w(k+2 \mid k) \\
\vdots & \vdots \\
\hat{y}(k+p \mid k)= & \hat{y}(k+p \mid k-1)+s_{p} \Delta u(k \mid k)+s_{p-1} \Delta u(k+1 \mid k)+\ldots+ \\
& +s_{1} \Delta u(k+p-1 \mid k)+w(k+p \mid k)
\end{array}
$$

where

- $*(k+i \mid k)$ is a prediction at sampling time $k+i$ based on information available at sampling time $k$,

- $*(k+j \mid k-1)$ is a prediction at sampling time $k+j$ based on information available at sampling time $k-1$,

- $w(* \mid *)$ represents effects of the disturbance on output prediction.

If assumed that the unmeasured disturbance will not change in the future, an estimate of it over the prediction horizon $p$ can be derived as a difference between the "real" measured output $y_{m}(k)$ and output prediction made in the previous step $\hat{y}(k \mid k-1)$ as:

$$
w(k \mid k)=w(k+1 \mid k)=w(k+2 \mid k)=\ldots=w(k+p \mid k) \approx y_{m}(k)-\hat{y}(k \mid k-1)
$$


The control variable $u$ is considered only over the control horizon $m$ which is shorter than the prediction horizon $p(m<p)$. Therefore, the input changes are set to zero for all inputs after the control horizon:

$$
\Delta u(k+m \mid k)=\Delta u(k+m+1 \mid k)=\ldots=\Delta u(k+p-1 \mid k)=0
$$

With the assumptions in (4.8) and (4.9), equation (4.7) can be written as:

$$
\begin{gathered}
{\left[\begin{array}{c}
\hat{y}(k+1 \mid k) \\
\hat{y}(k+2 \mid k) \\
\hat{y}(k+3 \mid k) \\
\vdots \\
\hat{y}(k+p \mid k)
\end{array}\right]=\left[\begin{array}{c}
\hat{y}(k+1 \mid k-1) \\
\hat{y}(k+2 \mid k-1) \\
\hat{y}(k+3 \mid k-1) \\
\vdots \\
\hat{y}(k+p \mid k-1)
\end{array}\right]+\left[\begin{array}{ccccc}
s_{1} & 0 & 0 & \cdots & 0 \\
s_{2} & s_{1} & 0 & \cdots & 0 \\
s_{3} & s_{2} & s_{1} & \cdots & 0 \\
\vdots & \vdots & \vdots & \ddots & \vdots \\
s_{p} & s_{p-1} & s_{p-2} & \cdots & s_{p-m+1}
\end{array}\right]\left[\begin{array}{c}
\Delta u(k \mid k) \\
\Delta u(k+1 \mid k) \\
\Delta u(k+2 \mid k) \\
\vdots \\
\Delta u(k+m-1 \mid k)
\end{array}\right]+} \\
+\left[\begin{array}{c}
y_{m}(k)-\hat{y}(k \mid k-1) \\
y_{m}(k)-\hat{y}(k \mid k-1) \\
y_{m}(k)-\hat{y}(k \mid k-1) \\
\vdots \\
y_{m}(k)-\hat{y}(k \mid k-1)
\end{array}\right]
\end{gathered}
$$

Note that $\hat{y}(k+p \mid k-1)$ is the $p+1$ element of the output prediction at sampling time $k-1$, just outside of the prediction horizon. Since the system is assumed settled after $p$ steps, there is no change in outputs after the prediction horizon expires. For that reason, it can be adopted that $\hat{y}(k+p \mid k-1)=\hat{y}(k+p-1 \mid k-1)$ as the output prediction in $p+1$ step.

Adopting the new notation that:

$$
\begin{gathered}
\hat{Y}(k+1 \mid k)_{p \times 1}=\left[\begin{array}{llll}
\hat{y}(k+1 \mid k) & \hat{y}(k+2 \mid k) & \ldots & \hat{y}(k+p \mid k)
\end{array}\right]^{T} \\
\hat{Y}(k \mid k-1)_{p \times 1}=\left[\begin{array}{llll}
\hat{y}(k \mid k-1) & \hat{y}(k+1 \mid k-1) & \ldots & \hat{y}(k+p-1 \mid k-1)
\end{array}\right]^{T} \\
\Delta U(k \mid k)_{m \times 1}=\left[\begin{array}{llll}
\Delta u(k \mid k) & \Delta u(k+1 \mid k) & \ldots & \Delta u(k+m-1 \mid k)
\end{array}\right]^{T} \\
S_{p \times m}=\left[\begin{array}{cccc}
s_{1} & 0 & \ldots & 0 \\
s_{2} & s_{1} & \ldots & 0 \\
\vdots & \vdots & \ddots & \vdots \\
s_{p} & s_{p-1} & \cdots & s_{p-m+1}
\end{array}\right]
\end{gathered}
$$




$$
P_{p \times 1}=\left[\begin{array}{llll}
1 & 1 & \ldots & 1
\end{array}\right]^{T}
$$

and introducing the "shifting" matrix $M$ as:

$$
M_{p \times p}=\left[\begin{array}{ccccc}
0 & 1 & 0 & \cdots & 0 \\
0 & 0 & 1 & \cdots & 0 \\
\vdots & \vdots & \vdots & \ddots & \vdots \\
0 & 0 & 0 & 0 & 1 \\
0 & 0 & 0 & 0 & 1
\end{array}\right]
$$

the prediction equation (4.10) written in a matrix form becomes:

$$
\hat{Y}(k+1 \mid k)=M \cdot \hat{Y}(k \mid k-1)+S \cdot \Delta U(k \mid k)+P \cdot\left(y_{m}(k)-\hat{y}(k \mid k-1)\right)
$$

\subsection{Performance index}

The performance index is chosen in a quadratic form:

$$
J=\sum_{i=1}^{p} q_{i}\left(\hat{y}(k+i \mid k)-y_{r}(k+i \mid k)\right)^{2}+\sum_{j=1}^{m} r_{j}(\Delta u(k+j-1 \mid k))^{2}
$$

minimized with respect to the sequence of input increments $\Delta u(k \mid k), \ldots, \Delta u(k+m-1 \mid k)$ :

$$
\min _{\Delta u(k \mid k), \ldots, \Delta u(k+m-1 \mid k)} J
$$

The criterion penalizes the weighted sum of the square of predicted output deviations $\hat{y}(k+i \mid k)$ from the reference trajectory $y_{r}(k+i \mid k)$, calculating an optimal sequence of control input changes $\Delta u(k \mid k)$. Coefficients $q_{i}$ and $r_{j}$ are the nonnegative weighting coefficients, and the larger weight means more contribution of the corresponding element in the performance index, that is, more penalties for that element.

The performance index (4.13) in a matrix form can be written as:

$$
\begin{gathered}
\min _{\Delta U(k \mid k)} J=\min _{\Delta U(k \mid k)}\{[\hat{Y}(k+1 \mid k) \\
\left.-Y_{r}(k+1 \mid k)\right]^{T} Q\left[\hat{Y}(k+1 \mid k)-Y_{r}(k+1 \mid k)\right]+ \\
\left.+[\Delta U(k \mid k)]^{T} R[\Delta U(k \mid k)]\right\}
\end{gathered}
$$


where

$$
Q_{p \times p}=\left[\begin{array}{cccc}
q_{1} & 0 & \cdots & 0 \\
0 & q_{2} & \cdots & 0 \\
\vdots & \vdots & \ddots & \vdots \\
0 & 0 & \cdots & q_{p}
\end{array}\right] \quad \text { and } \quad R_{m \times m}=\left[\begin{array}{cccc}
r_{1} & 0 & \cdots & 0 \\
0 & r_{2} & \cdots & 0 \\
\vdots & \vdots & \ddots & \vdots \\
0 & 0 & \cdots & r_{m}
\end{array}\right]
$$

Substituting $\hat{Y}(k+1 \mid k)$ in equation (4.14) with (4.11) yields:

$$
\begin{gathered}
J=[E(k)+S \cdot \Delta U(k \mid k)]^{T} Q[E(k)+S \cdot \Delta U(k \mid k)]+ \\
+\Delta U(k \mid k)^{T} \cdot R \cdot \Delta U(k \mid k)
\end{gathered}
$$

where the term $E(k)$ :

$$
E(k)=M \cdot \hat{Y}(k \mid k-1)+P \cdot\left(y_{m}(k)-\hat{y}(k \mid k-1)\right)-Y_{r}(k+1 \mid k)
$$

represents the error vector of the output prediction from the reference trajectory, with an assumption that all future changes in the system input $\Delta U(k \mid k)$ are set to zero.

Expanding equation (4.15):

$$
\begin{gathered}
J=E(k)^{T} Q E(k)+E(k)^{T} Q S \Delta U(k \mid k)+\Delta U(k \mid k)^{T} S^{T} Q E(k)+ \\
+\Delta U(k \mid k)^{T} S^{T} Q S \Delta U(k \mid k)+\Delta U(k \mid k)^{T} R \Delta U(k \mid k)
\end{gathered}
$$

and with $E(k)^{T} Q S \Delta U(k \mid k)=\Delta U(k \mid k)^{T} S^{T} Q E(k)$, we can write:

$$
\begin{gathered}
J=E(k)^{T} Q E(k)+2 E(k)^{T} Q S \Delta U(k \mid k)+ \\
+\Delta U(k \mid k)^{T}\left[S^{T} Q S+R\right] \Delta U(k \mid k)
\end{gathered}
$$

The first part of the performance index $J$ in equation (4.18), $E(k)^{T} Q E(k)$, does not depend on the change of control input sequence $\Delta U(k \mid k)$ (equation (4.16)) and it is a constant during the optimization procedure within the sample $k$, hence, it can be excluded from the optimization procedure. Therefore, the performance index given with equation (4.14) can be written as a Quadratic Programing (QP) problem:

$$
\min _{\Delta U(k \mid k)} J=\min _{\Delta U(k \mid k)} \frac{1}{2} \Delta U(k \mid k)^{T} H \Delta U(k \mid k)+f(k)^{T} \Delta U(k \mid k)
$$

with

$$
\begin{aligned}
& H=2\left[S^{T} Q S+R\right] \\
& f(k)=2 S^{T} Q E(k)
\end{aligned}
$$




\subsection{Constraints}

Many control problems express requirements for constraints on the system variables. The constraints can be imposed on the manipulated as well as state and/or output variables. The constraints can be expressed as a variable saturation, variable rate change, or to keep the variable within certain bounds.

Including constraints imposed on the system, the performance index (4.13) becomes:

$$
\begin{aligned}
& \min _{\Delta u(k \mid k), \ldots, \Delta u(k+m-1)} J= \\
& \qquad \min _{\Delta u(k \mid k), \ldots, \Delta u(k+m-1)} \sum_{i=1}^{p} q_{i}\left(\hat{y}(k+i \mid k)-y_{r}(k+i \mid k)\right)^{2}+\sum_{j=1}^{m} r_{j}(\Delta u(k+j-1 \mid k))^{2} \\
& \text { s.t. } \quad\left\{\begin{array}{l}
y_{i}^{\min } \leq \hat{y}(k+i \mid k) \leq y_{i}^{\max } \\
u_{j-1}^{\min } \leq u(k+j-1 \mid k) \leq u_{j-1}^{\max } \\
\Delta u_{j-1}^{\min } \leq \Delta u(k+j-1 \mid k) \leq \Delta u_{j-1}^{\max }
\end{array}\right.
\end{aligned}
$$

where $y_{i}^{\min }, y_{i}^{\max }, u_{j-1}^{\min }, u_{j-1}^{\max }, \Delta u_{j-1}^{\min }, \Delta u_{j-1}^{\max }$ are the lower/upper bounds to be enforced. The input and input-change constraints are treated as hard constraints, while the output constraints are considered as soft.

The output constraints in matrix form are:

$$
Y_{\min } \leq \hat{Y}(k+1 \mid k) \leq Y_{\max }
$$

where

$$
\begin{aligned}
Y_{\min } & =\left[\begin{array}{llll}
y_{1}^{\min } & y_{2}^{\min } & \ldots & y_{p}^{\min }
\end{array}\right]^{T} \\
Y_{\max } & =\left[\begin{array}{llll}
y_{1}^{\max } & y_{2}^{\max } & \ldots & y_{p}^{\max }
\end{array}\right]^{T}
\end{aligned}
$$

Substituting $\hat{Y}(k+1 \mid k)$ in (4.22) with equation (4.11),

$$
Y_{\min } \leq M \cdot \hat{Y}(k \mid k-1)+S \cdot \Delta U(k \mid k)+P \cdot\left(y_{m}(k)-\hat{y}(k \mid k-1)\right) \leq Y_{\max }
$$

the output constraints can be expressed as a function of $\Delta U(k \mid k)$ as:

$$
\begin{aligned}
S \cdot \Delta U(k \mid k) & \leq Y_{\max }-M \cdot \hat{Y}(k \mid k-1)-P \cdot\left(y_{m}(k)-\hat{y}(k \mid k-1)\right) \\
-S \cdot \Delta U(k \mid k) & \leq-Y_{\min }+M \cdot \hat{Y}(k \mid k-1)+P \cdot\left(y_{m}(k)-\hat{y}(k \mid k-1)\right)
\end{aligned}
$$


or:

$$
\left[\begin{array}{c}
S \\
-S
\end{array}\right] \Delta U(k \mid k) \leq\left[\begin{array}{c}
Y_{\max }-M \cdot \hat{Y}(k \mid k-1)-P \cdot\left(y_{m}(k)-\hat{y}(k \mid k-1)\right) \\
-Y_{\min }+M \cdot \hat{Y}(k \mid k-1)+P \cdot\left(y_{m}(k)-\hat{y}(k \mid k-1)\right)
\end{array}\right]
$$

Saturation constraints on the input variable can be expressed as:

$$
U_{\min } \leq U(k \mid k) \leq U_{\max }
$$

where

$$
\begin{aligned}
U_{\min } & =\left[\begin{array}{llll}
u_{0}^{\min } & u_{1}^{\min } & \ldots & u_{m-1}^{\min }
\end{array}\right]^{T} \\
U_{\max } & =\left[\begin{array}{llll}
u_{0}^{\max } & u_{1}^{\max } & \ldots & u_{m-1}^{\max }
\end{array}\right]^{T} \\
U(k \mid k) & =\left[\begin{array}{llll}
u(k \mid k) & u(k+1 \mid k) & \ldots & u(k+m-1 \mid k)
\end{array}\right]^{T}
\end{aligned}
$$

Elements of $U(k \mid k)$ can be calculated as:

$$
\begin{aligned}
& u(k \mid k)=u(k-1)+\Delta u(k \mid k) \\
& u(k+1 \mid k)=u(k-1)+\Delta u(k \mid k)+\Delta u(k+1 \mid k) \\
& \quad \vdots \\
& u(k+m-1 \mid k)=u(k-1)+\Delta u(k \mid k)+\ldots+\Delta u(k+m-1 \mid k)
\end{aligned}
$$

or in matrix form:

$$
U(k \mid k)=\mathbf{1}_{m \times 1} \cdot u(k-1)+L \cdot \Delta U(k \mid k)
$$

where $u(k-1)$ is the input calculated in the previous step, and

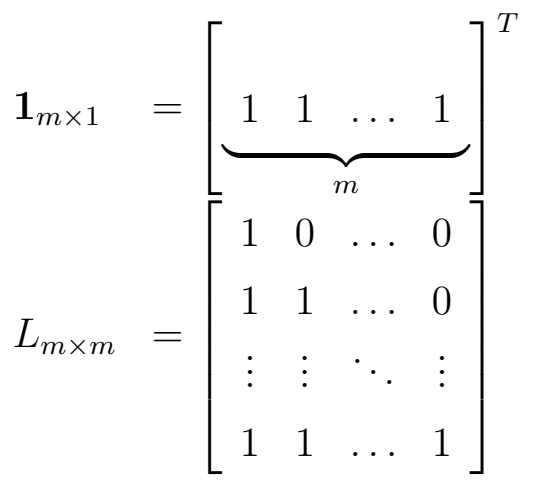

Substituting (4.28) into (4.26)

$$
U_{\min } \leq \mathbf{1}_{m \times 1} \cdot u(k-1)+L \cdot \Delta U(k \mid k) \leq U_{\max }
$$


the constraints can be expressed as a function of $\Delta U(k \mid k)$ as:

$$
\begin{aligned}
L \cdot \Delta U(k \mid k) & \leq U_{\max }-\mathbf{1}_{m \times 1} \cdot u(k-1) \\
-L \cdot \Delta U(k \mid k) & \leq-U_{\min }+\mathbf{1}_{m \times 1} \cdot u(k-1)
\end{aligned}
$$

or:

$$
\left[\begin{array}{c}
L \\
-L
\end{array}\right] \Delta U(k \mid k) \leq\left[\begin{array}{c}
U_{\max }-\mathbf{1}_{m \times 1} \cdot u(k-1) \\
-U_{\min }+\mathbf{1}_{m \times 1} \cdot u(k-1)
\end{array}\right]
$$

Rate constraints on the input variable can be expressed as:

$$
\Delta U_{\min } \leq I_{m \times m} \cdot \Delta U(k \mid k) \leq \Delta U_{\max }
$$

where

$$
\begin{aligned}
\Delta U_{\min } & =\left[\begin{array}{llll}
\Delta u_{0}^{\min } & \Delta u_{1}^{\min } & \ldots & \Delta u_{m-1}^{\min }
\end{array}\right]^{T} \\
\Delta U_{\max } & =\left[\begin{array}{llll}
\Delta u_{0}^{\max } & \Delta u_{1}^{\max } & \ldots & \Delta u_{m-1}^{\max }
\end{array}\right]^{T}
\end{aligned}
$$

Constraints (4.32) can be also written as:

$$
\begin{aligned}
I_{m \times m} \cdot \Delta U(k \mid k) & \leq \Delta U_{\max } \\
-I_{m \times m} \cdot \Delta U(k \mid k) & \leq-\Delta U_{\min }
\end{aligned}
$$

or:

$$
\left[\begin{array}{c}
I_{m \times m} \\
-I_{m \times m}
\end{array}\right] \Delta U(k \mid k) \leq\left[\begin{array}{c}
\Delta U_{\max } \\
-\Delta U_{\min }
\end{array}\right]
$$

Including the constraints derived with equations (4.25), (4.31) and (4.34) into (4.19), the constrained optimization problem (4.21) becomes:

$$
\min _{\Delta U(k \mid k)} J=\min _{\Delta U(k \mid k)} \frac{1}{2} \Delta U(k \mid k)^{T} H \Delta U(k \mid k)+f^{T} \Delta U(k \mid k)
$$

$$
A \cdot \Delta U(k \mid k) \leq b
$$

where

$$
A=\left[\begin{array}{c}
S \\
-S \\
L \\
-L \\
I_{m \times m} \\
-I_{m \times m}
\end{array}\right] ; \quad b=\left[\begin{array}{c}
Y_{\max }-M \cdot \hat{Y}(k \mid k-1)-P \cdot\left(y_{m}(k)-\hat{y}(k \mid k-1)\right) \\
-Y_{\min }+M \cdot \hat{Y}(k \mid k-1)+P \cdot\left(y_{m}(k)-\hat{y}(k \mid k-1)\right) \\
U_{\max }-\mathbf{1}_{m \times 1} u(k-1) \\
-U_{\min }+\mathbf{1}_{m \times 1} u(k-1) \\
\Delta U_{\max } \\
-\Delta U_{\min }
\end{array}\right]
$$




\subsection{An MPC Algorithm}

An MPC algorithm for constrained problem is:

1. Pre-process: Choose sampling interval $\Delta t$, prediction and control horizons $p$ and $m$, and set $k=0$. Compute the step response coefficient matrix $S$. Initialize weighting coefficient matrices $Q$ and $R$, reference trajectory $Y_{r}$ and control input $u(0)$. Compute matrix $H$, equation (4.20) and initialize the QP constraints matrix $A$, equation (4.36). Obtain current measurements $y_{m}(0)$ and initialize $\hat{Y}(0)$ and $\Delta U(0)$ :

$$
\begin{aligned}
& \hat{Y}(0)_{p \times 1}=\left[\begin{array}{llll}
y_{m}(0) & y_{m}(0) & \ldots & y_{m}(0)
\end{array}\right]^{T} \\
& \Delta U(0)_{m \times 1}=\left[\begin{array}{llll}
0 & 0 & \ldots & 0
\end{array}\right]^{T}
\end{aligned}
$$

2. Obtain measurements $y_{m}(k)$.

3. Update the reference $Y_{r}(k+1 \mid k)$ and constraints $A$. Compute the error vector $E(k)$, equation (4.16), QP gradient vector $f(k)$, equation (4.20) and QP constraint matrix $b$, equation (4.36):

$$
\begin{aligned}
& E(k)=M \cdot \hat{Y}(k \mid k-1)+P \cdot\left(y_{m}(k)-\hat{y}(k \mid k-1)\right)-Y_{r}(k+1 \mid k) \\
& f(k)=2 S^{T} Q E(k) \\
& b=\left[\begin{array}{c}
Y_{\max }-M \cdot \hat{Y}(k \mid k-1)-P \cdot\left(y_{m}(k)-\hat{y}(k \mid k-1)\right) \\
-Y_{\min }+M \cdot \hat{Y}(k \mid k-1)+P \cdot\left(y_{m}(k)-\hat{y}(k \mid k-1)\right) \\
U_{\max }-\mathbf{1}_{p \times 1} u(k-1) \\
-U_{\min }+\mathbf{1}_{p \times 1} u(k-1) \\
\Delta U_{\max } \\
-\Delta U_{\min }
\end{array}\right]
\end{aligned}
$$

4. Solve the constrained QP problem, equation (4.35):

$$
\Delta U(k \mid k)=Q P \_ \text {solver }(H, f, A, b)
$$

and implement the first element $\Delta u(k \mid k)$ on the plant:

$$
u(k)=u(k-1)+\Delta u(k \mid k)
$$


5. Compute the output prediction $\hat{Y}(k+1 \mid k)$, equation (4.11):

$$
\hat{Y}(k+1 \mid k)=M \cdot \hat{Y}(k \mid k-1)+S \cdot \Delta U(k \mid k)+P \cdot\left(y_{m}(k)-\hat{y}(k \mid k-1)\right)
$$

6. Set $\mathrm{k}=\mathrm{k}+1$ and wait for the next sampling time. Go to Step 2 and repeat. 


\section{Chapter 5}

\section{Model Predictive Load Frequency Control}

In this chapter a Load Frequency Control technique based on the Model Predictive Control algorithm described in Chapter 4 will be applied on a test power system model within the Matlab/Simulink environment. First, information about chosen test system will be presented, then the control algorithm will be given, and, finally, the simulation results will be discussed.

\section{$5.1 \quad$ Test system}

The test system, shown in Figure 5.1, consists of three control areas interconnected through high voltage tie-lines, with three generation companies (Gencos) within each area.

The control areas are responsible for their own native load and to maintain the interarea power exchange contracts. The areas are modeled as presented in Chapter 3.2, where each Genco within the area has one generating unit. The governors and turbines of generating units are modeled as one-stage transfer functions, while in order to get the frequency deviation of a control area, the generators within the area are lumped together into one transfer function. The generating unit parameters are tabulated in Table 5.1, and the tie-line synchronizing power coefficients are: $T_{12}=180 \mathrm{MW} / \mathrm{rad}, T_{13}=200 \mathrm{MW} / \mathrm{rad}$ and $T_{23}=120 M W /$ rad . 


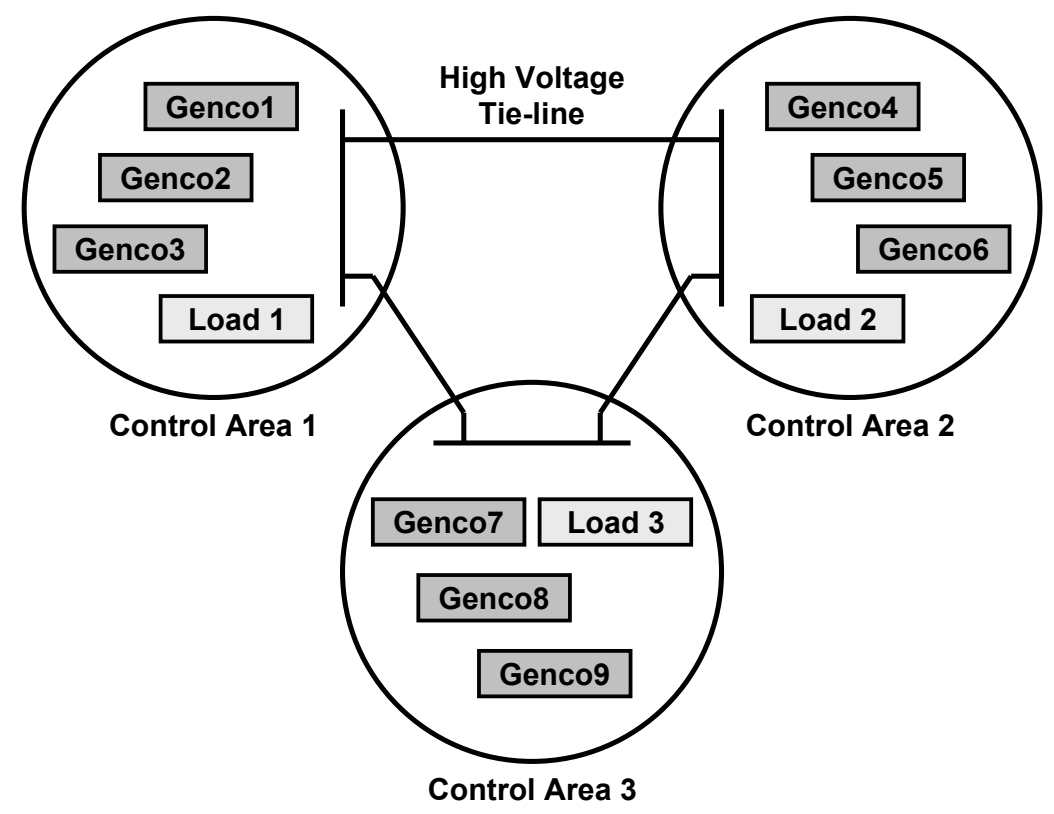

Figure 5.1: Three-area test system

This classical system representation is quite common in the literature and studies [7], [12], [26]. The simulation results obtained with this type of a model showed no significant differences, when compared to those obtained using the Power Analysis Toolbox (PAT) package, where the power system components are modeled with more details [8].

Table 5.1: Parameters of generating units

\begin{tabular}{|c|c|c|c|c|c|c|c|c|c|}
\hline Parameters & \multicolumn{9}{|c|}{ Generation Company (Genco) } \\
\hline $\begin{array}{c}S_{\text {base }}= \\
(1000 \mathrm{MW})\end{array}$ & 1 & 2 & 3 & 4 & 5 & 6 & 7 & 8 & 9 \\
\hline Rate $(\mathrm{MW})$ & 1000 & 800 & 1000 & 1100 & 900 & 1200 & 850 & 1000 & 1020 \\
\hline$D(\mathrm{pu} / \mathrm{Hz})$ & 0.0150 & 0.0140 & 0.0150 & 0.0160 & 0.0140 & 0.0140 & 0.0150 & 0.0160 & 0.0150 \\
\hline$T_{P}(\mathrm{pu} . \mathrm{sec})$ & 0.1667 & 0.1200 & 0.2000 & 0.2017 & 0.1500 & 0.1960 & 0.1247 & 0.1667 & 0.1870 \\
\hline$T_{T}(\mathrm{sec})$ & 0.4 & 0.36 & 0.42 & 0.44 & 0.32 & 0.40 & 0.30 & 0.40 & 0.41 \\
\hline$T_{H}(\mathrm{sec})$ & 0.08 & 0.06 & 0.07 & 0.06 & 0.06 & 0.08 & 0.07 & 0.07 & 0.08 \\
\hline$R(\mathrm{~Hz} / \mathrm{pu})$ & 3.00 & 3.00 & 3.30 & 2.7273 & 2.6667 & 2.50 & 2.8235 & 3.00 & 2.9412 \\
\hline$B(\mathrm{pu} / \mathrm{Hz})$ & 0.3483 & 0.3473 & 0.3180 & 0.3827 & 0.3890 & 0.4140 & 0.3692 & 0.3493 & 0.3550 \\
\hline$\alpha$ & 0.4 & 0.2 & 0.4 & 0.3 & 0.2 & 0.5 & 0 & 0.5 & 0.5 \\
\hline
\end{tabular}




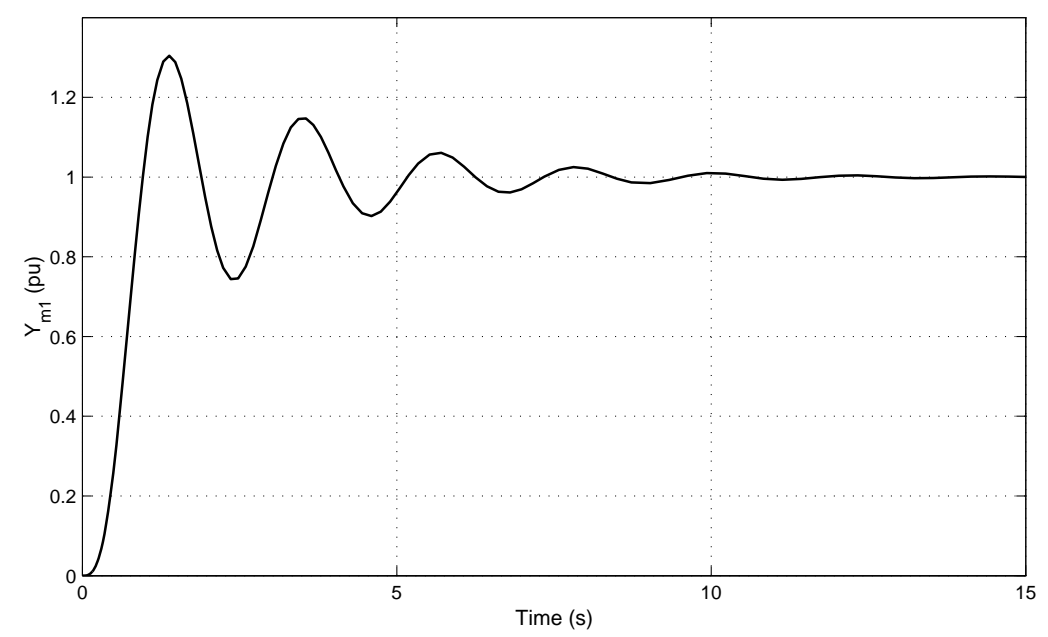

Figure 5.2: Area 1 step response

\subsection{Controller design}

The basis for the controller design is given in Chapters 3 and 4 . It is very important to choose a proper sampling time $\Delta t$, since the computational burden can be too high if chosen too short, or the control performance can be unacceptable if chosen too long. The prediction and control horizons $p$ and $m$ directly depend on the chosen sampling interval as well as on the system settling time. Figure 5.2 is an output response of the control area 1 model to the unit step input. It is visible that the system comes to the rest in less than 15 seconds after the step input is applied. Similar settling time is observed with models of control areas 2 and 3 in the test system. This means that with the sampling interval of 0.5 seconds, the control horizon of 15 samples $(m=15)$ and prediction horizon of 40 samples $(p=40)$ are of appropriate length to achieve good control performance with manageable computations in real-time.

Constraints in the system are defined with the physical characteristics of the system. They can be expressed in a form of saturation of the generator set point $\left(P_{c}^{\min }\right.$ and $\left.P_{c}^{\max }\right)$, limits on the generation rate change (GRC) $\left(\Delta P_{c}^{\text {down }}\right.$ and $\left.\Delta P_{c}^{u p}\right)$, or as bounds on the system output $\left(A C E^{\mathrm{min}}\right.$ and $\left.A C E^{\mathrm{max}}\right)$.

Area Control Error in each control area is taken as the system output, and it is measured in every sampling interval. If the generation within one control area matches its local obliga- 
tion and inter-area power exchange contracts, the ACE is zero. Hence, the control objective is to keep the ACE at zero value, therefore the reference trajectory is set to 0 all the time: $Y_{r}(k)=0 ; \forall k$.

After choosing the sampling time $\Delta t$, prediction and control horizons $p$ and $m$, defining the system constraints, and setting the reference trajectory, the control algorithm as presented in Chapter 4.4 is followed in every sampling interval. Routines and functions from the MPC and Optimization toolboxes ([27], [25]) are used to calculate the control inputs, and the simulation is provided within the Matlab/Simuling environment.

\subsection{Simulation results}

Performance of the proposed controllers is tested on four different load scenarios:

- Random load changes,

- Large load disturbances in all control areas,

- Loss of a generating unit in Control Area 1, and

- Generating Rate Constraint handling.

The reasons for proposed scenarios are to 1) show the controllers' performance during power system normal operation, 2) test the robustness of the controllers in an emergency situation such as sudden load change or generating unit loss, and 3) test the ability to cope with constraints on control variables. Results of nonlinear simulations are presented and compared to those obtained using PI controllers. The parameters (gains) for the PI controllers are selected using the GALMI technique [7], and given in Table 5.2.

Table 5.2: PI Gains

\begin{tabular}{|c|c|c|c|}
\hline Gains & Area 1 & Area 2 & Area 3 \\
\hline$K_{P}$ & 0 & 0 & -0.0253 \\
\hline$K_{I}$ & -0.2805 & -0.3358 & -0.32 \\
\hline
\end{tabular}



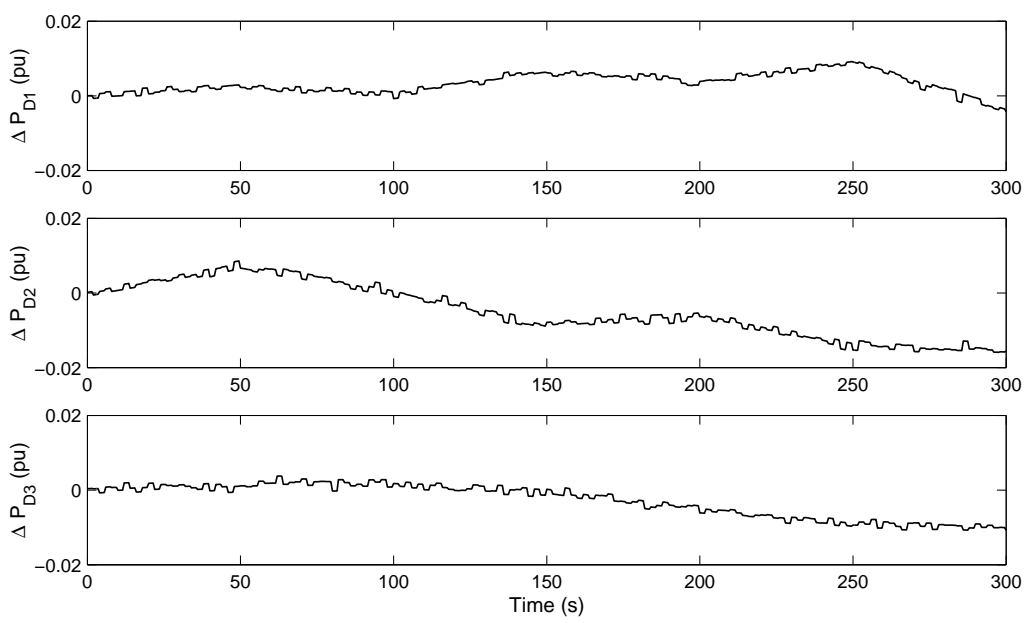

Figure 5.3: Random load changes

\subsubsection{Random load changes}

Random load changes shown in Figure 5.3 represent expected changes in demand $\Delta P_{D 1}$, $\Delta P_{D 2}$ and $\Delta P_{D 3}$ in respective control areas during 300 seconds of simulation time. Those fluctuations in power demand are common in power systems operation, and the purpose of this scenario is to check a behavior of the proposed MPC controller under normal operating conditions. Figures 5.4(a), 5.4(b) and 5.4(c) present closed-loop responses of the governor set point $\left(\Delta P_{C}\right)$, area control error $(A C E)$ and frequency deviation $(\Delta f)$ for control area 1 , 2 and 3 respectively. Analyzing the simulation results it can be observed that both type of controllers (MPC and GALMI PI) adjust the governor set points effectively, responding to the demand changes in timely manner. The $A C E$ signal and frequency deviation are very small and within acceptable limits. From the results it can be concluded that both type of controllers produce adequate control actions and behave in similar manner.

\subsubsection{Large load disturbances in all control areas}

In this section, effects of large load disturbance and corresponding corrective control actions are investigated. Step increases in demand of $\Delta P_{D 1}=150 \mathrm{MW}, \Delta P_{D 2}=120 \mathrm{MW}$ and $\Delta P_{D 3}=100 \mathrm{MW}$ are applied in control areas 1, 2 and 3 respectively. The purpose of this scenario is to test robustness of the proposed controller against sudden changes in demand. 


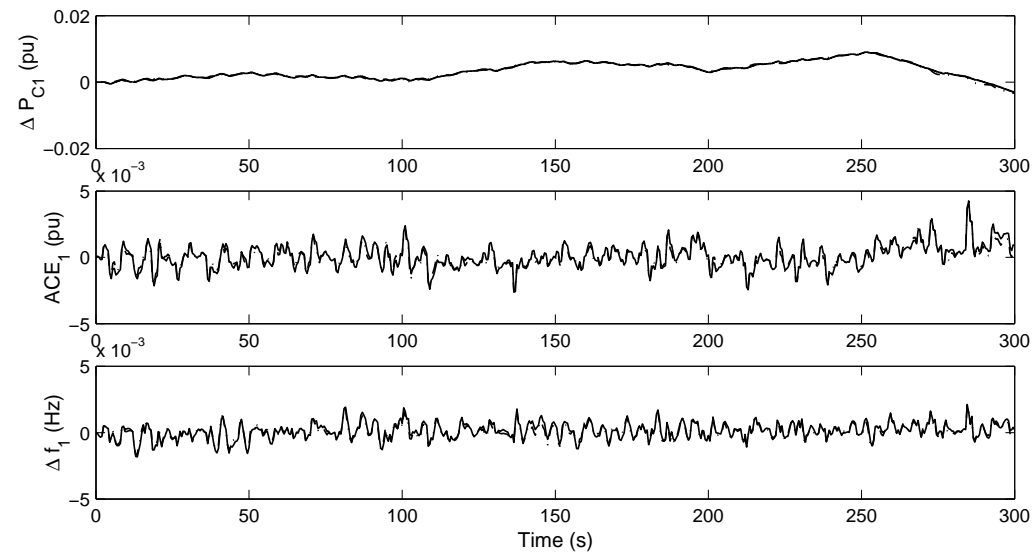

(a) Area 1
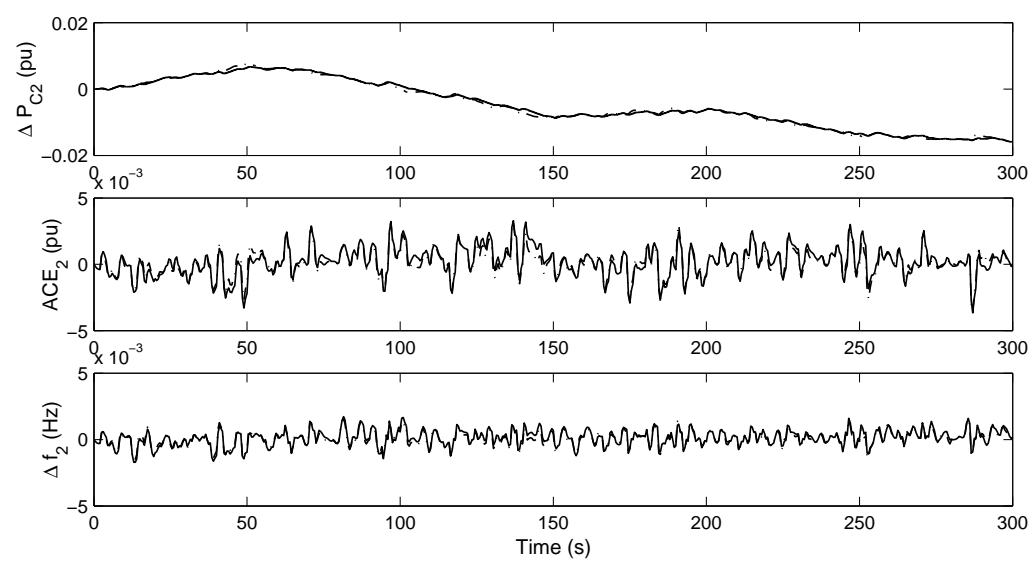

(b) Area 2

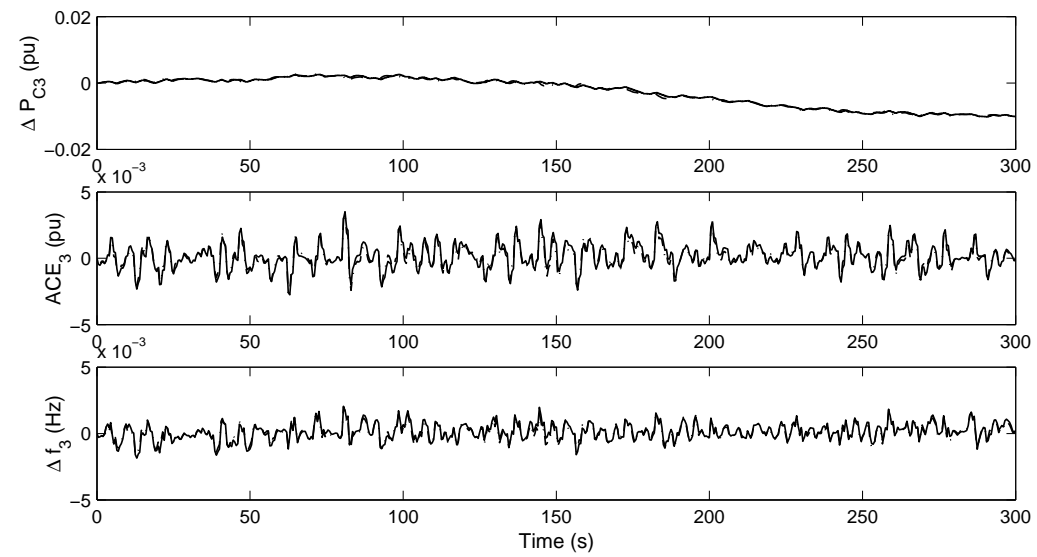

(c) Area 3

Figure 5.4: System response for Scenario 1. MPC - Solid, PI - Dash-dotted 
For this case, generating rate constraint (GRC) was not imposed on the system. As for the previous scenario, closed-loop responses of the governor set point $\left(\Delta P_{C}\right)$, area control error $(A C E)$ and frequency deviation $(\Delta f)$ of control areas 1, 2 and 3 are identified as important, and they are presented in Figures 5.5(a), 5.5(b) and 5.5(c). It can be observed that the control inputs $\Delta P_{C}$ in all control areas are efficiently increased to match the demand, without overshoots and oscillations. The $A C E$ and frequency deviation $\Delta f$ are driven to zero shortly after the disturbance occured, with very small oscillations. Under this type of scenario, the MPC controller performs somewhat better than the GALMI tuned PI controllers.

\subsubsection{Loss of a generating unit in Control Area 1}

As its name says, model predictive control algorithm is based on a system model, and precise model of the controlled system is required for good results. However, small inaccuracies in the identified model are treated as an unmeasured disturbance and adjusted through the error correction between the actual and predicted system output.

This scenario tests the robustness of the proposed controller under a severe condition such is a loss of a generating unit, when the model in use suddenly becomes inaccurate. Changes in power demand are the same as for Scenario 1 (Section 5.3.1), with unexpected failure of the generating unit 2 in control area 1 at time $t=5 \mathrm{sec}$. The fault is simulated by disconnecting the Simulink blocks representing the unit 2, and imposing a step increase in demand for the value of load that was carried by the unit 2 in the moment of failure. An assumption is made that the control area 1 has enough reserve in the remaining generation to cover for the loss of unit 2 (600MW or 0.6p.u. for this scenario). The simulation results are divided into two parts, the first period of 30 seconds that covers the fault and the transient period (Figures 5.6(a), 5.6(b) and 5.6(c)), and the second period that includes time after the 30th second of simulation when the control actions have adjusted the governor set points of the remaining generation for the loss of generating unit 2 (Figures 5.7(a), 5.7(b) and 5.7(c)). The results of the first part of simulation show that the control input $\Delta P_{C 1}$ of control area 1 was steadily increased to cover for the demand without overshoots, with the $A C E_{1}$ and frequency deviation $\Delta f_{1}$ driven to zero in a fast manner. Control areas 2 and 3 have experienced some oscillations during the transient period, with all the signals returning to their pre-fault values 

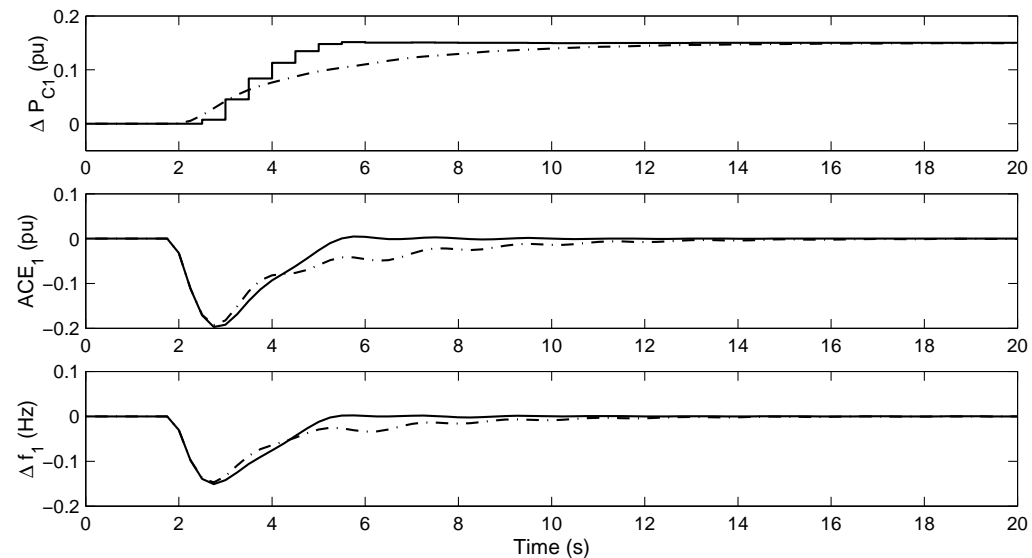

(a) Area 1
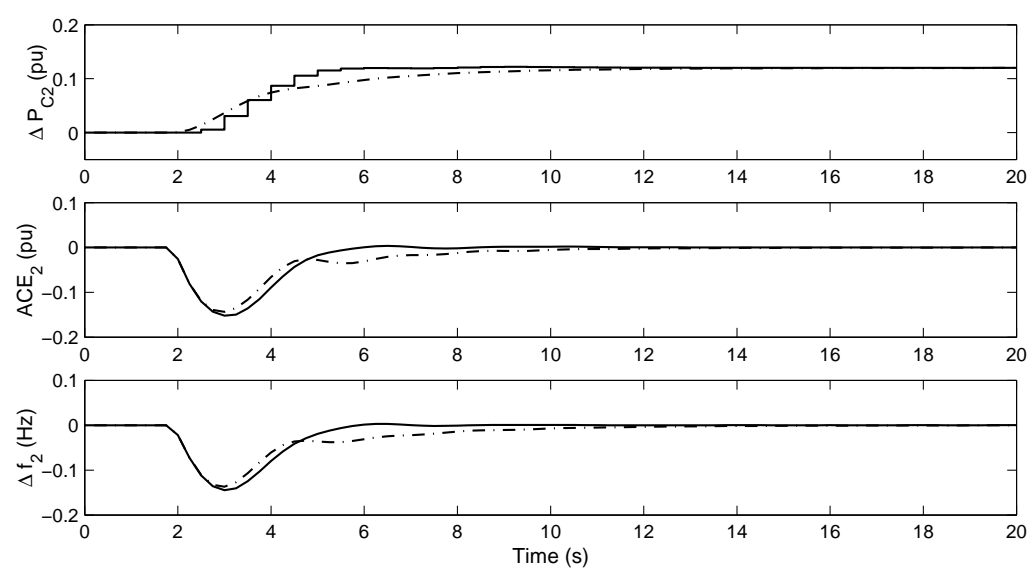

(b) Area 2
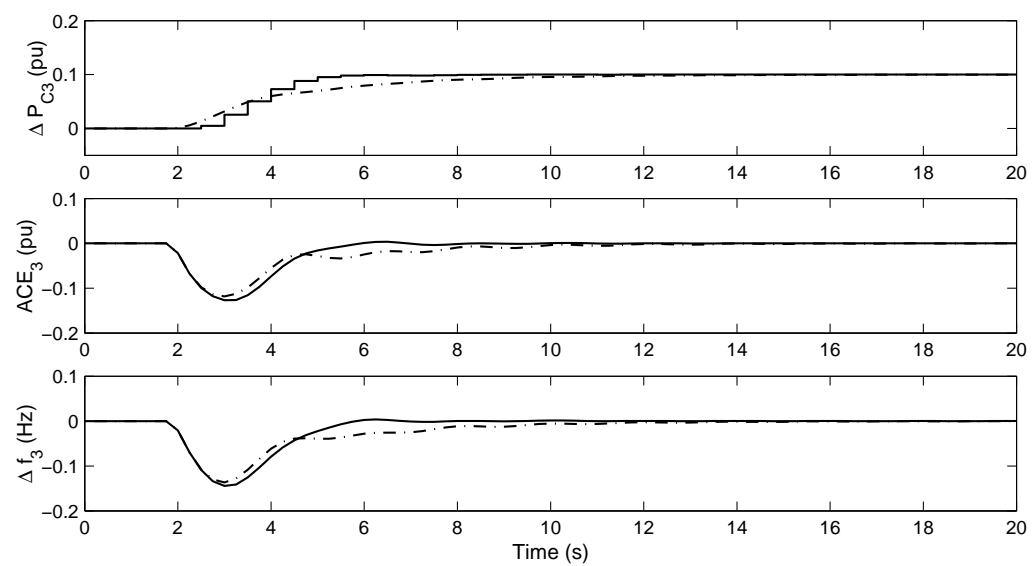

(c) Area 3

Figure 5.5: System response for Scenario 2. MPC - Solid, PI - Dash-dotted 
after settling the oscillations down. It is noticeable that the controller "requested" $0.75 p . u$. of power in control area 1 instead of $0.6 p . u$. that the unit 2 carried before the fault. The discrepancy is due to the fact that the contribution of the Genco 2 in the LFC of the control area 1 was 20\%, against $80 \%$ for the other two Gencos combined (Table 5.1). Therefore, the remaining units "receive" only $80 \%$ of the control signal which converted into numbers in our case means $0.75 p . u . \times 0.8=0.6 p . u$. The second part of simulation showed similar closed-loop responses to those in scenario 1 , with the $A C E$ and frequency deviation $\Delta f$ very close to zero in all three areas. The performance of the MPC controllers is slightly better that of the PI controllers, with faster recovery time and less oscilations.

This scenario has shown robustness of the proposed control design against severe conditions, giving enough time to the operator to make appropriate actions, such is rescheduling of the existing generation or introducing the reserves, and to update the system model within the control algorithm with more accurate one.

\subsubsection{Generating Rate Constraint handling}

In this scenario, the same load disturbance as in Scenario 2 (Section 5.3.2) is applied in each area. Additionally, a generating rate constraint (GRC) of 150MW/5 min has been imposed on each area. The purpose of this scenario is to test the robustness of the proposed control scheme under large disturbance in power demand, while handling the GRC at the same time. The closed-loop responses from all control areas are shown in Figures 5.8(a), 5.8(b) and 5.8(c). A longer simulation time of 2000 seconds is considered in order to fully observe effects of the GRC on the control performance. The responses show that the proposed MPC controllers successfully bring the system back to the stable operating point in around 300 seconds ( 5 minutes) after the disturbance occured without any oscillations and overshoots. At the same time, the system controlled by the PI controllers is experiencing severe oscillations without achieving the stable point even after 2000 seconds of simulation time. The superior performance of the MPC controller is achieved due to the fact that the MPC algorithm incorporates hard constraints on the rate of change of control inputs as a part of the optimization procedure. 

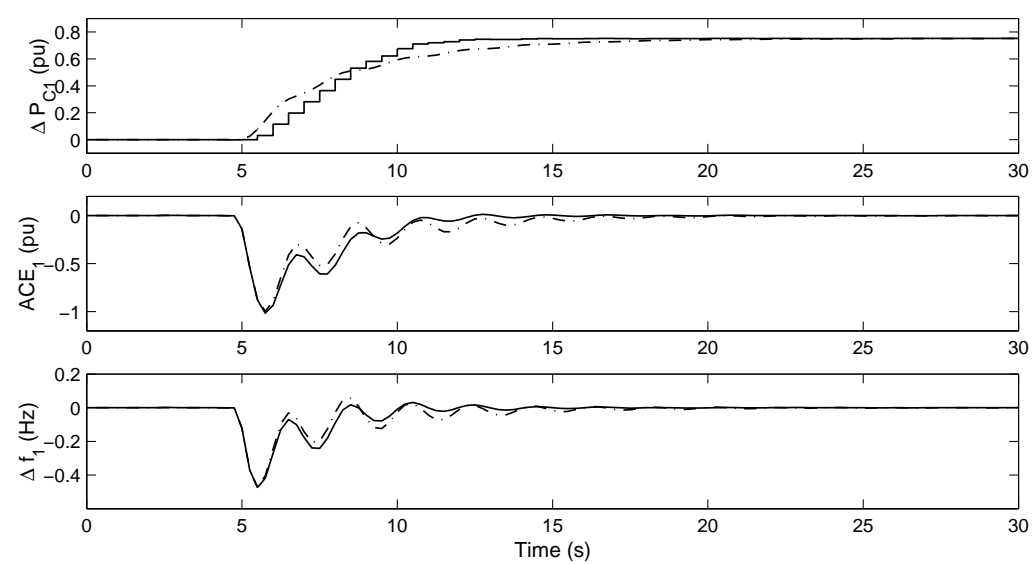

(a) Area 1
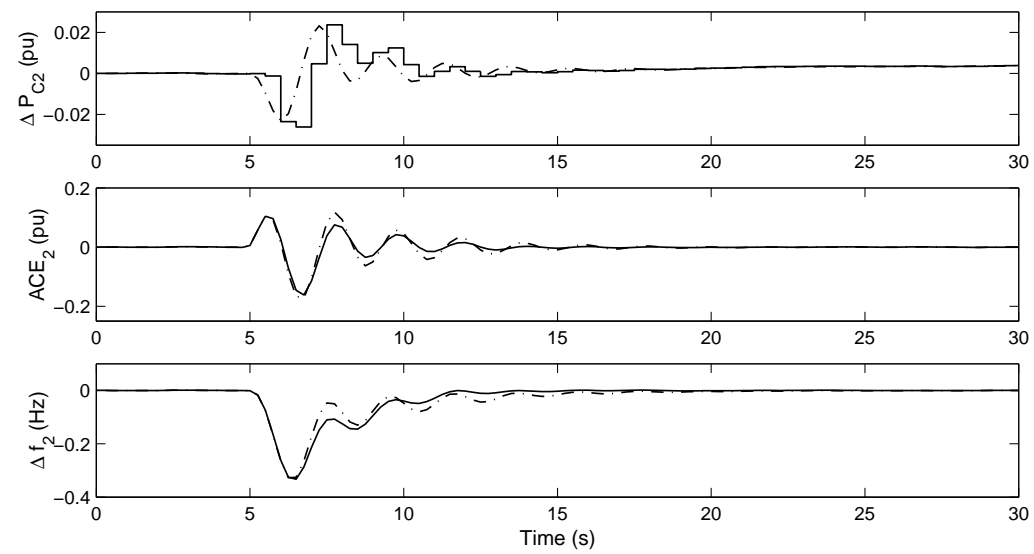

(b) Area 2
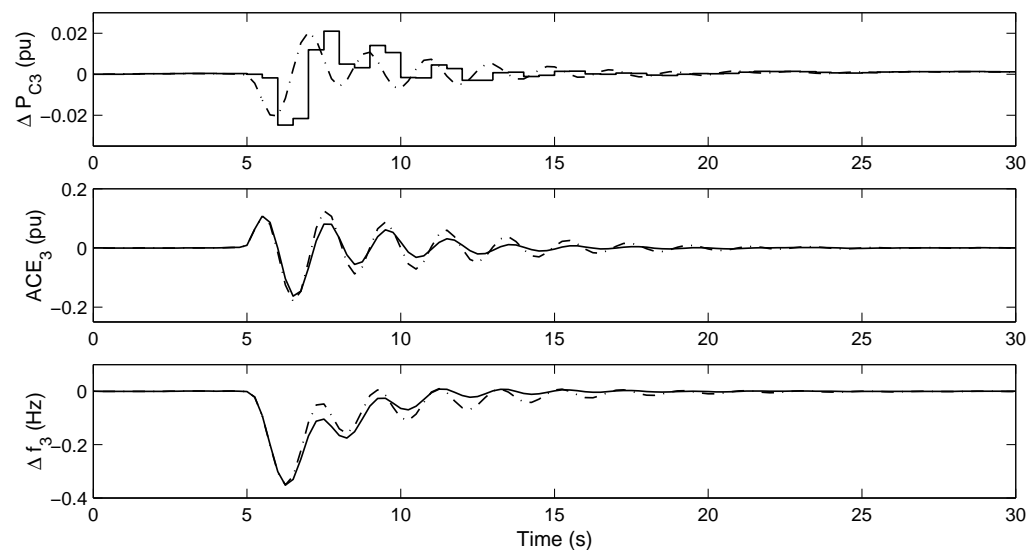

(c) Area 3

Figure 5.6: System response for Scenario 3, first period. MPC - Solid, PI - Dash-dotted 


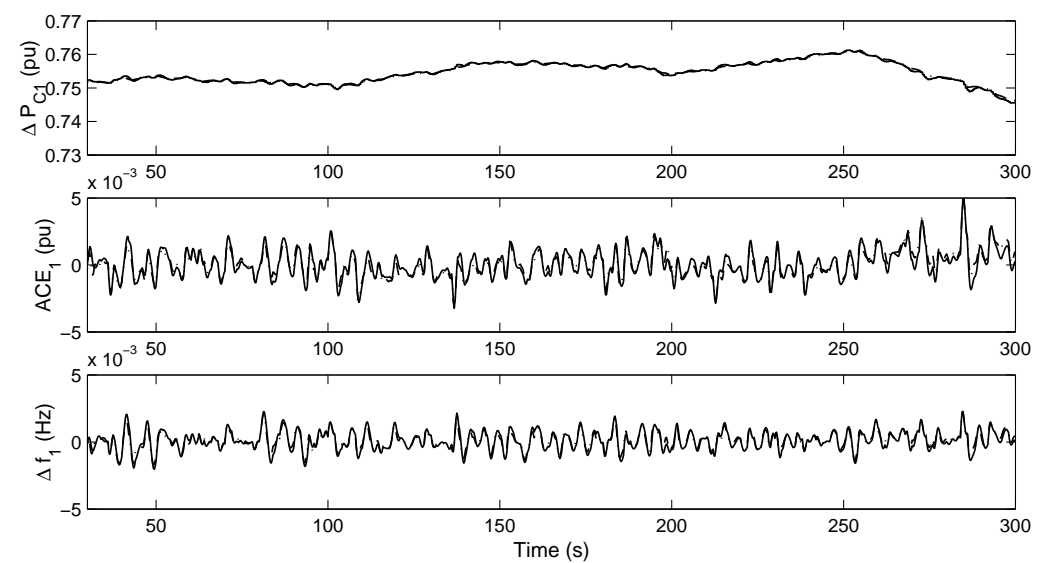

(a) Area 1
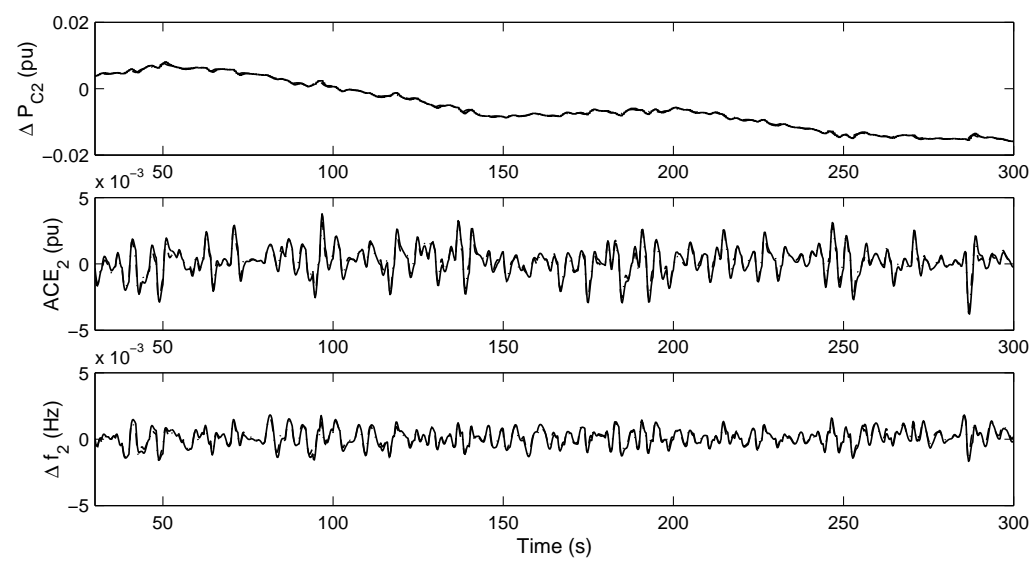

(b) Area 2
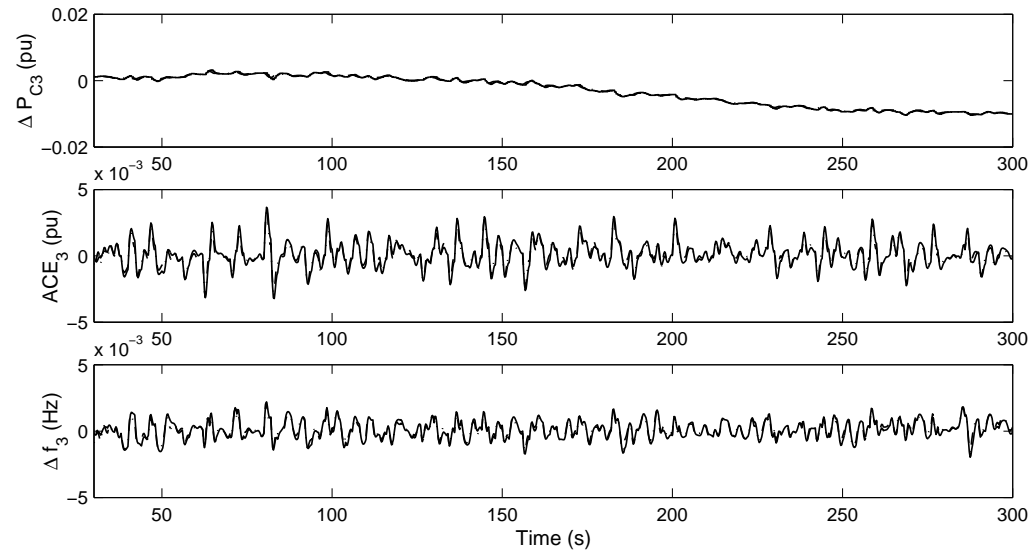

(c) Area 3

Figure 5.7: System response for Scenario 3, second period. MPC - Solid, PI - Dash-dotted 

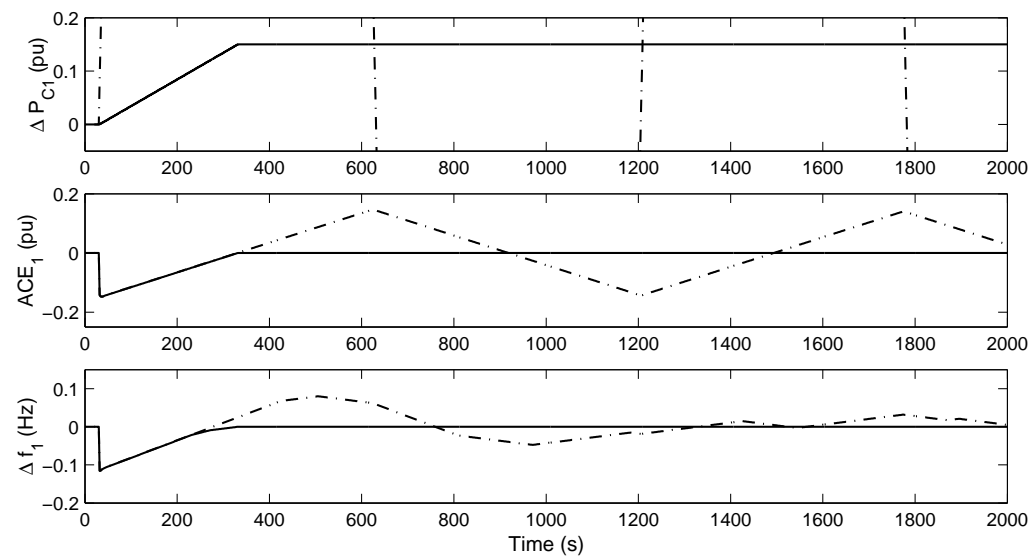

(a) Area 1
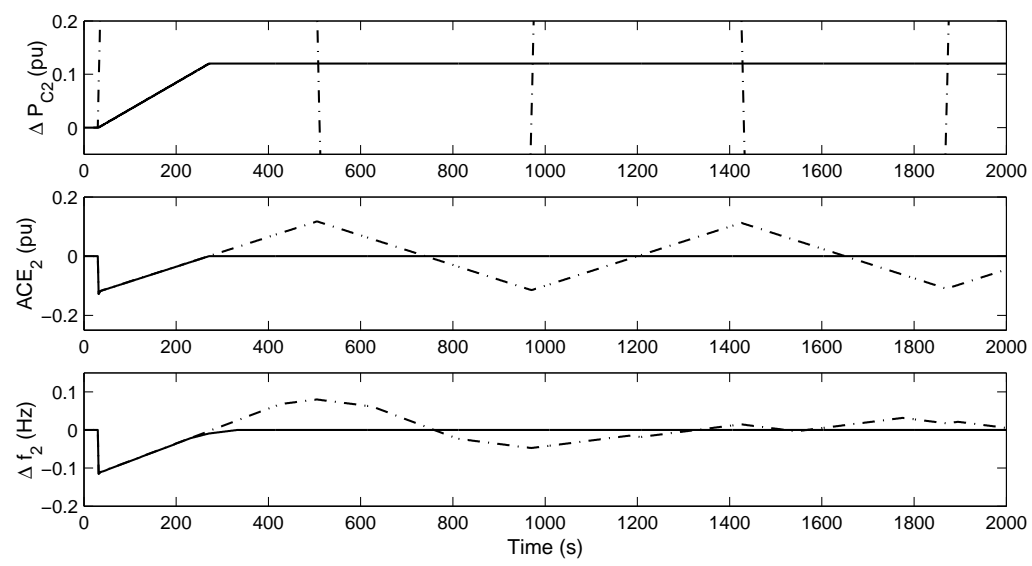

(b) Area 2
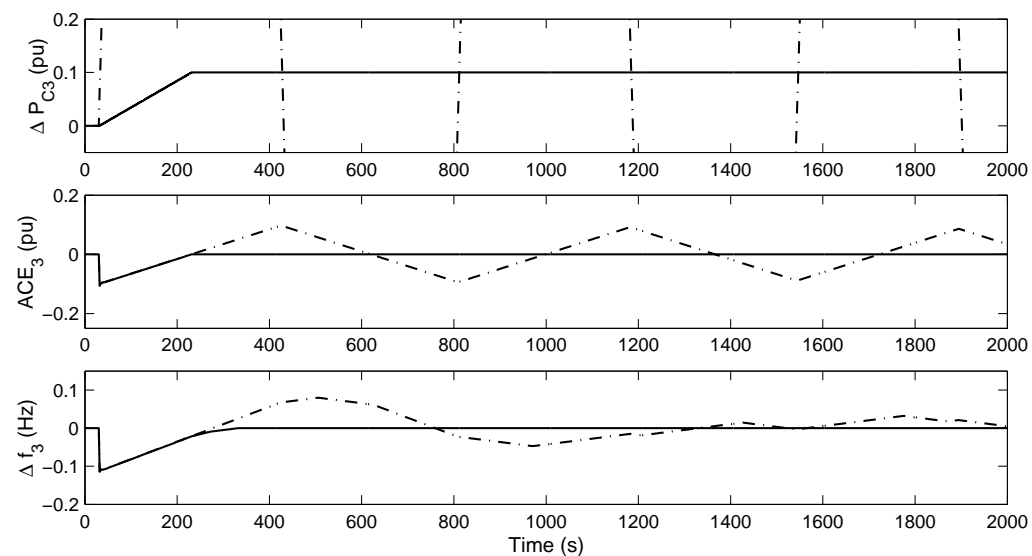

(c) Area 3

Figure 5.8: System response for Scenario 4. MPC - Solid, PI - Dash-dotted 


\section{Chapter 6}

\section{NERC compliant Model Predictive LFC}

This chapter presents a decentralized Model Predictive Load Frequency Control algorithm with two main objectives, (1) to assure control area compliance with control performance standards CPS1 and CPS2, and (2) to reduce wear and tear of generating units. A nonlinear simulation of a test system with multiple generation and distribution companies including load following and regulation contracts is performed to illustrate the proposed control scheme.

\subsection{Test system}

To assess the performance of the proposed controller, a three-area interconnected power system is chosen, as presented in Figure 6.1. The test system includes five Gencos and three Discos competing in the market. Control area 1 and control area 2 have two Gencos and one Disco each, while Area 3 has only one Genco and one Disco.

In order to satisfy customers' power demand, Discos call for load following and regulation services from Gencos. After their bids and offers are matched, those services are provided by Gencos according to established contracts [28],[29].

Load following contracts: Generating units that provide the load following service will ramp their generation to follow slow load fluctuations which are estimated based on the time period of the day, day in a week, season, weather forecast, etc. In the test system, this 


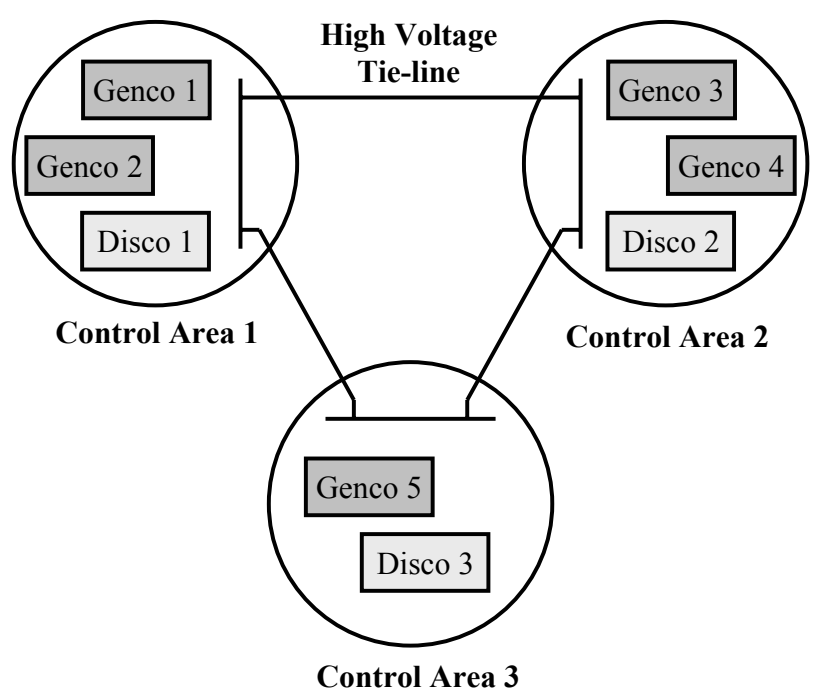

Figure 6.1: Three-area test system

service is taken into account, and the contracts are given in Table 6.1.

Regulation contracts: Fast fluctuations in power demand cannot be matched by load following services. Consequently, resultant mismatches represented in the ACE signal are taken care by those units providing regulation services [30]. The regulation contracts for the test system are given in Table 6.2.

Table 6.1: Load Following Contracts

\begin{tabular}{|c|c|c|c|}
\hline & DISCO 1 & DISCO 2 & DISCO 3 \\
\hline GENCO 1 & $80 \%$ & $20 \%$ & - \\
\hline GENCO 2 & - & - & - \\
\hline GENCO 3 & - & $50 \%$ & - \\
\hline GENCO 4 & - & - & - \\
\hline GENCO 5 & $20 \%$ & $30 \%$ & $100 \%$ \\
\hline
\end{tabular}

Table 6.2: Regulation Contracts

\begin{tabular}{|c|c|c|c|}
\hline & ACE1 & ACE2 & ACE3 \\
\hline GENCO 1 & - & - & - \\
\hline GENCO 2 & $100 \%$ & - & - \\
\hline GENCO 3 & - & $50 \%$ & - \\
\hline GENCO 4 & - & $50 \%$ & - \\
\hline GENCO 5 & - & - & $100 \%$ \\
\hline
\end{tabular}




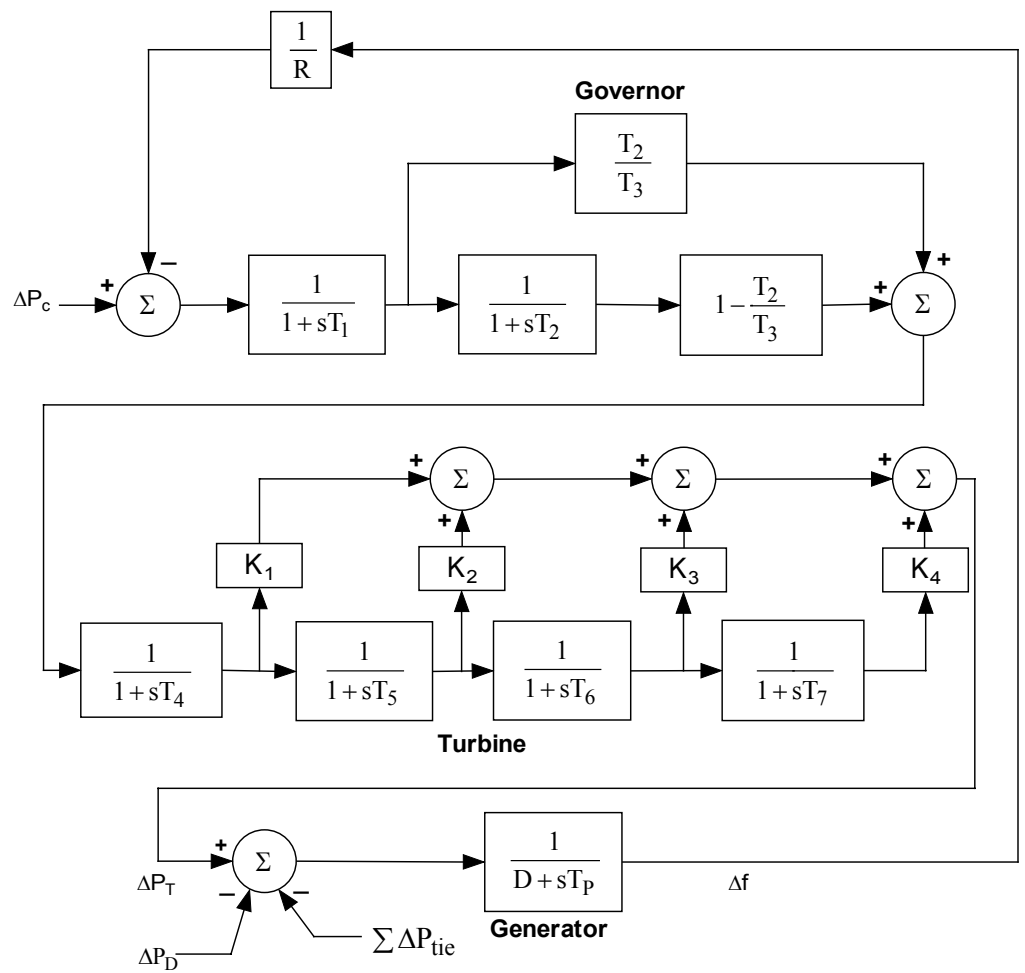

Figure 6.2: Generating unit and prime mover model

The model of a generating unit and prime mover is shown in Figure 6.2, with the turbine and governor modeled from several stages, and generators within one area lumped into one block. The parameters are given in Table 6.3, and the synchronizing power coefficients of the tie lines are: $T_{12}=200 \mathrm{MW} / \mathrm{rad}, T_{13}=250 \mathrm{MW} / \mathrm{rad}$ and $T_{23}=200 \mathrm{MW} / \mathrm{rad}$.

\subsection{Controller Design}

The basis for the design is given in Chapters 4 and 5.2, with the upper/lower bounds for governor setpoint $\left(\Delta u_{i}^{\min }\right.$ and $\left.\Delta u_{i}^{\max }\right)$ calculated in every sampling interval as:

$$
\begin{aligned}
& \Delta u_{i}^{\min }=c \times \Delta P_{c_{i}}^{\text {down }} \\
& \Delta u_{i}^{\max }=c \times \Delta P_{c_{i}}^{\text {up }} \\
& c=\max \left(c_{1}, c_{2}\right)
\end{aligned}
$$

where $\Delta P_{c_{i}}^{\text {down }}$ and $\Delta P_{c_{i}}^{u p}$ are the limits of the governor setpoint changes based on the area ramp rate, $c_{1}$ is a coefficient calculated based on a level of compliance with CPS1 and $c_{2}$ is 
Table 6.3: Generating Unit Parameters

\begin{tabular}{|l|c|c|c|c|}
\hline DATA & GENCO 1 & GENCO 2 \& 3 & GENCO 4 & GENCO \\
\hline Rating (MW) & 1000 & 750 & 700 & 2000 \\
\hline R & $5 \%$ & $4 \%$ & $4 \%$ & $5 \%$ \\
\hline D $(\mathrm{pu} \mathrm{MW/Hz)}$ & 20 & 15 & 14 & 18 \\
\hline H $(\mathrm{s})$ & 5 & 5 & 5 & 5 \\
\hline T1 & 2.8 & 3 & 2.7 & 2.5 \\
\hline T2 & 1 & 0 & 0 & 0 \\
\hline T3 & 0.15 & 1 & 1 & 1 \\
\hline T4 & 0.2 & 0.4 & 0.35 & 0.5 \\
\hline T5 & 6 & 0 & 0 & 5 \\
\hline T6 & 7 & 0 & 0 & 0 \\
\hline T7 & 0.5 & 0 & 0 & 0 \\
\hline K1 & 0.2 & 1 & 1 & 0.4 \\
\hline K2 & 0.2 & 0 & 0 & 0.6 \\
\hline K3 & 0.4 & 0 & 0 & 0 \\
\hline K4 & 0.2 & 0 & 0 & 0 \\
\hline
\end{tabular}

calculated based on 10-minute sliding window average of ACE divided with the area constant $L_{10}\left(W I N_{10}[A C E] / L_{10}\right)$ as a measure of compliance with CPS2.

To calculate $c_{1}$, the accumulated average compliance factor $\left(C F_{a c}\right)$ defined in $(6.2)$ is used.

$$
C F_{a c}=A V G_{A \rightarrow C}\left[C F_{1}\right]
$$

Point $\mathbf{C}$ in Figure 6.2 presents the current time, and $C F_{a c}$ is calculated every minute over

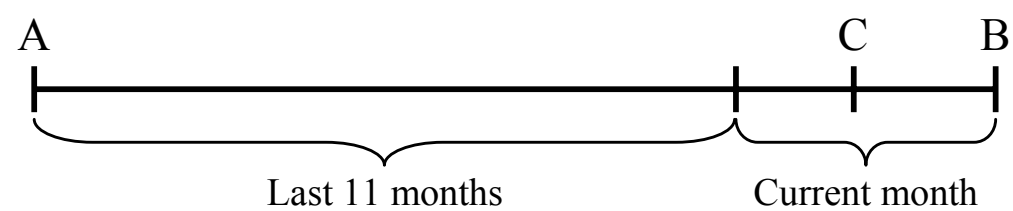

Figure 6.3: Sliding 12-month time line for $C F_{a c}$

the period $A \rightarrow C$. Point $\mathbf{B}$ presents an end of a sliding 12 -month period $A \rightarrow B$, when each area is required to report its level of compliance to the NERC. The coefficient $c_{1}$ is then calculated as:

$$
c_{1}= \begin{cases}1 & \text { if } C F_{a c} \leq C P S 1_{\min } \\ 0 & \text { if } C F_{a c}>C P S 1_{\min }\end{cases}
$$


where $C P S 1_{\min }$ is a threshold for minimum level of compliance. Since the CPS1 is calculated as a 12 month average of clock-1-minute information, it is not going to change rapidly, so $C P S 1_{\min }$ should be around $100 \%$ which is defined by the NERC as a minimum level of compliance with CPS1. The value of $C P S 1_{\min }$ can be changed dynamicaly to higher or lower level based on past CPS1 performance.

The coefficient $c_{2}$ is calculated from the ratio between 10-minute sliding window average of $\mathrm{ACE}\left(W I N_{10}[A C E]\right)$ and the $L_{10}$ coefficient as follows:

$$
c_{2}= \begin{cases}0 & \text { if } W I N_{10}[A C E] / L_{10} \leq 0.5 \\ W I N_{10}[A C E] / L_{10} & \text { if } 0.5<W I N_{10}[A C E] / L_{10} \leq 1 \\ 1 & \text { if } W I N_{10}[A C E] / L_{10}>1 \text { or } C P S 2<C P S 2_{\text {min }}\end{cases}
$$

where $C P S 2_{\min }$ is a threshold for minimum level of compliance, and it should be close to 90 $\%$ which is defined by the NERC as a minimum level of compliance with CPS2.

Once the $c_{1}, c_{2}$, and the lower/upper limits for the governor setpoints $\Delta u_{i}^{\min }$ and $\Delta u_{i}^{\max }$ are calculated with (6.3), (6.4) and (6.1), an optimal control input can be calculated solving the optimization problem (4.35). The maximum value of the coefficients is set to 1 since there is no need to change the governor setpoint with more efforts and any faster than the control area ramp rate value. If the control area is in good compliance with the CPS1 and CPS2, then the $c_{1}$ and $c_{2}$ coefficients are set to zero, hence there is no action taken in that sampling interval. In a case of bad compliance, the optimization procedure given with equation (4.35) will result in an optimal control input, satisfying constraints calculated with equation (6.1).

\subsection{Simulation results}

The algorithm proposed in Chapter 6.2 is applied to the test system under a load pick-up hour scenario. Figure 6.4 represents expected load changes that consist of linear components, supposed to be satisfied with the load following services, and random components, which are supposed to be met by the regulation services.

The performance of the NERC compliant MPC controller is assessed through a nonlinear simulation, and simulation results are compared to those obtained using the MPLFC control algorithm as presented in Chapter 5.2 with objective to bring the ACE signal to zero as soon 

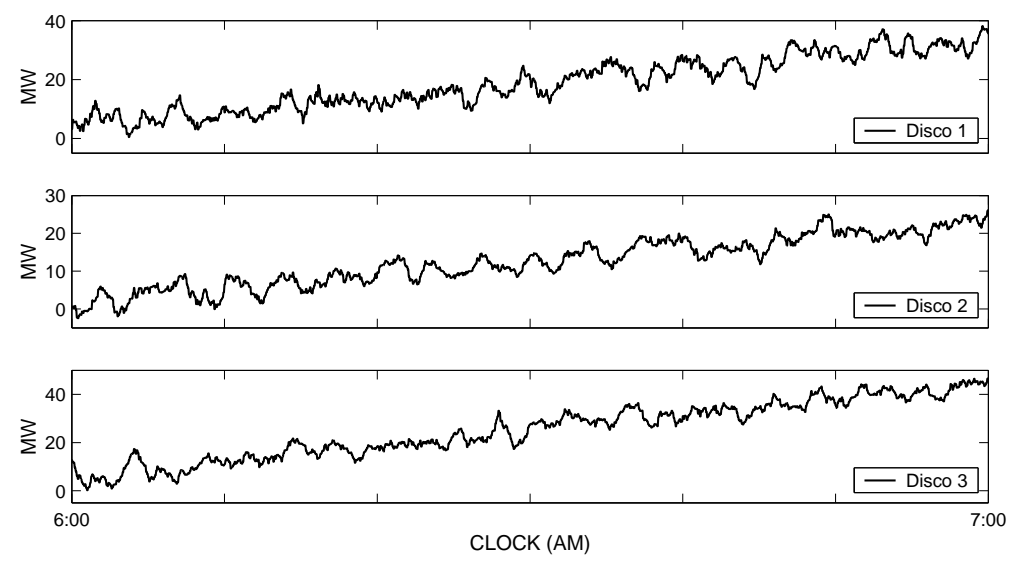

Figure 6.4: Aggregate load changes

as possible after occurrence of disturbance (coefficient $c$ in (6.1) set to 1).

Figure 6.5 represents changes in governor setpoints $\left(\Delta P_{c}\right)$ of each generating unit for the two type of controllers. Excessive maneuvering of the controllers can be observed in the case when the MPLFC controllers were used, while the NERC compliant MPC controllers make changes in the governor setpoints only when necessary to keep control areas in good compliance with the NERC standards, with time intervals as long as 10 minutes without control action.

Prior to simulation, all areas in the test system are assumed to be in high compliance with CPS1. The percentages of compliance for all control areas over the hour under observation are presented in Figure 6.6. Analyzing the simulation results, the NERC compliant MPC controllers have increased the value of CPS1 in all three areas. In the case of the MPLFC control strategy, the CPS1 is raising faster as it was expected. That gives good assurance of a CPS1 recovery to the control areas that use the NERC compliant MPC algorithm when the compliance drops below the threshold value $C P S 1_{\min }$ in which case the NERC compliant MPC controller becomes the MPLFC type controller.

Figure 6.7 presents $A V G_{10-m i n u t e}[A C E]$ for all three control areas as a factor of compliance with CPS2. If the $A V G_{10-m i n u t e}[A C E]$ value is above $L_{10}$ (thick solid line), that counts as a violation for any 10-minute interval lowering the compliance down. For the case when the full MPLFC control is implemented, the value of $A V G_{10-m i n u t e}[A C E]$ is very low for all intervals due to the stiff control, while in the case of NERC compliant MPC controllers, 


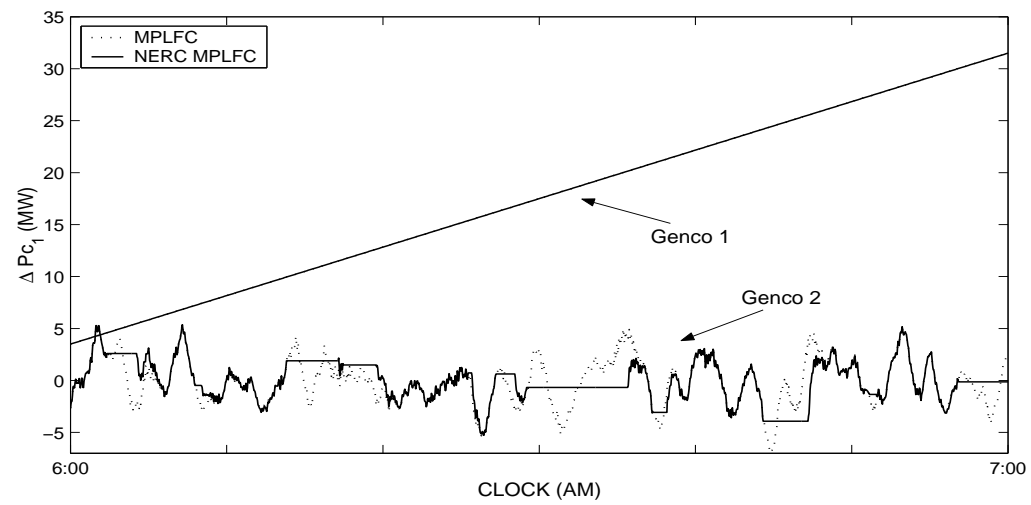

(a) Area 1

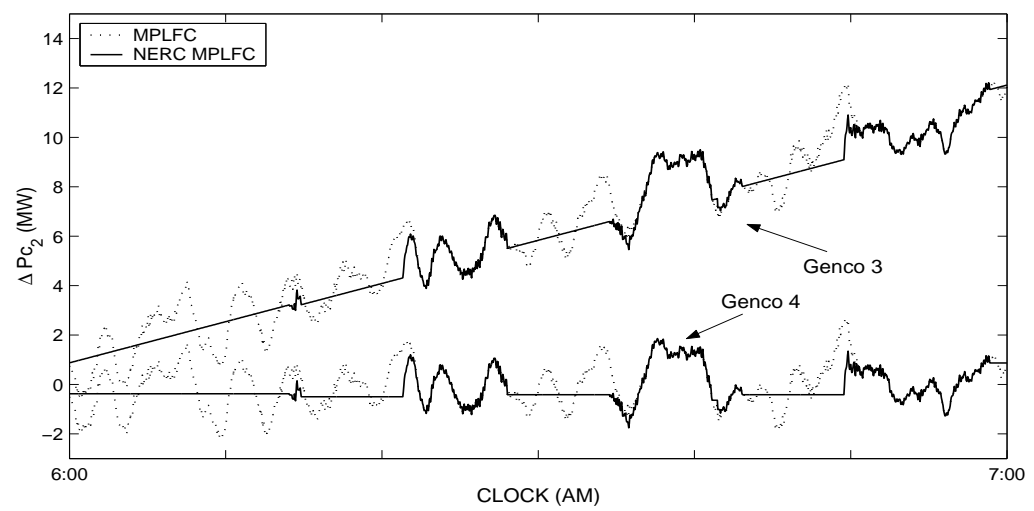

(b) Area 2

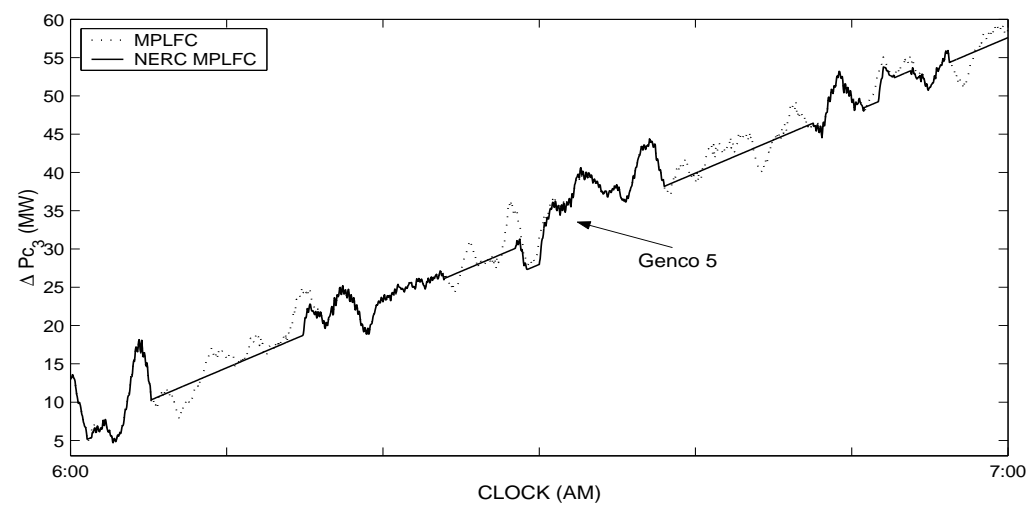

(c) Area 3

Figure 6.5: Raise/Lower signals of each generating unit 

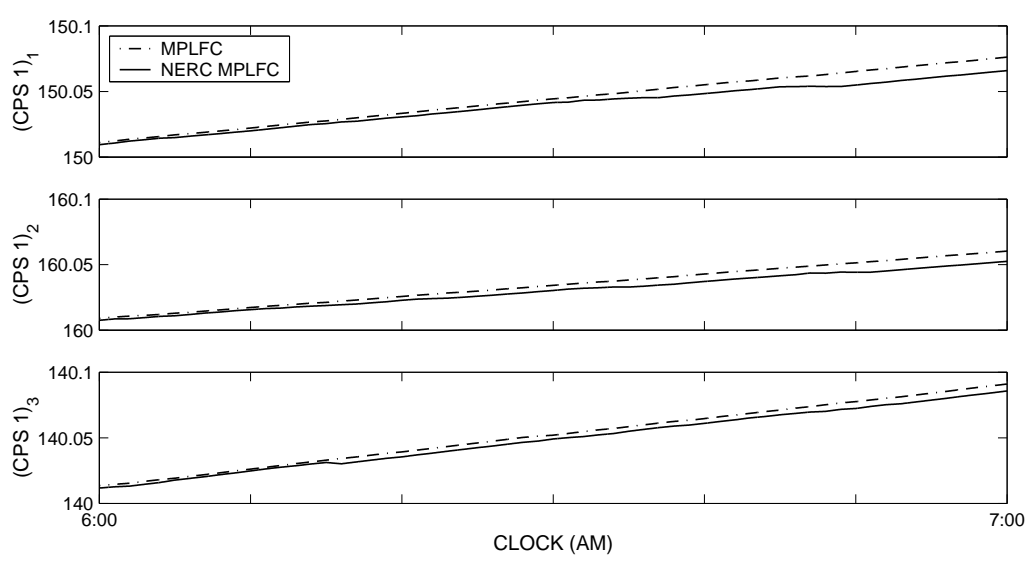

Figure 6.6: CPS1 compliance
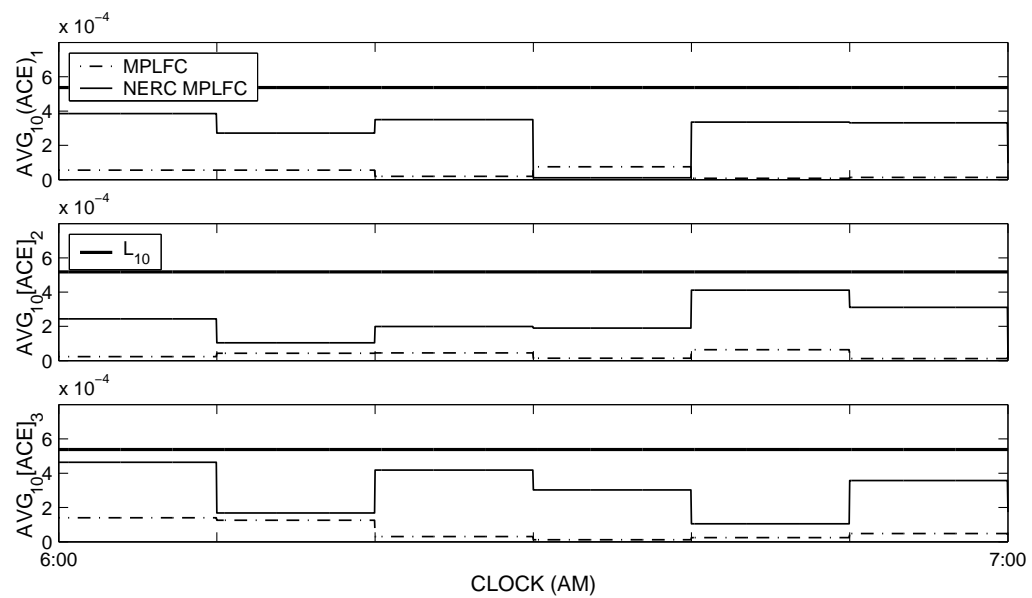

Figure 6.7: 10-minute average of $\mathrm{ACE}-A V G_{10}[A C E]$
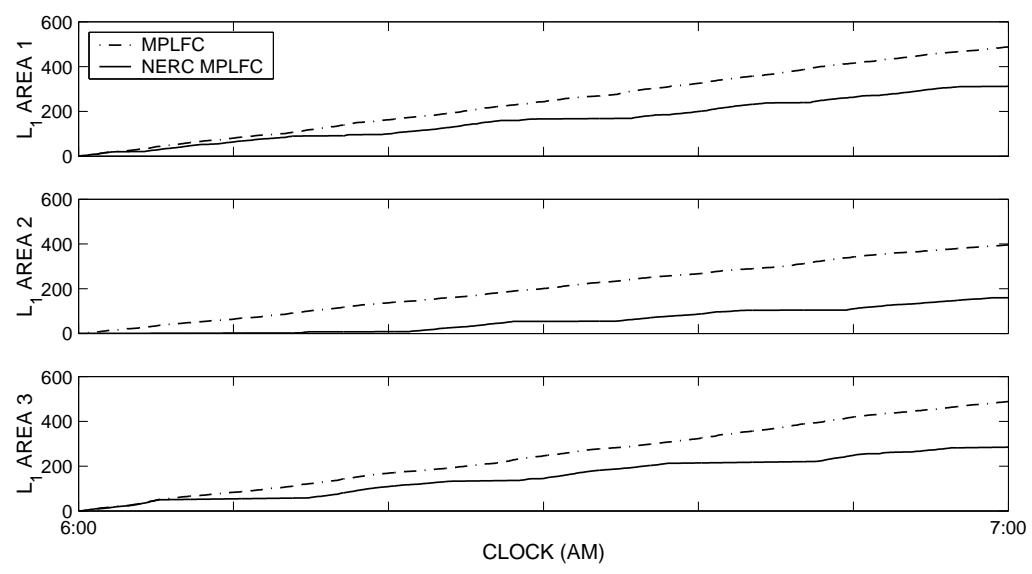

Figure 6.8: $L 1$ norm for all three areas 
it is higher for all of the 10 minute intervals in all control areas, but still under $L_{10}$. It is observed that the NERC compliant MPC controllers successfully keep the control areas in compliance with CPS2 and at the same time reduce wear and tear on the generating units.

$L_{1}$ norm of the LFC control effort, $L_{1}=\sum\left|\Delta P_{c}\right|$ is chosen to present the accumulated maneuvering of the generating units. The $L_{1}$ norm is associated with the unit wear and tear, and its change over the simulated hour of operation is shown in Figure 6.8. It can be observed that the NERC compliant MPC technique yields significantly lower value of the $L_{1}$ norm than in the case of the MPLFC control.

The other measure of wear and tear are unit reversals. Frequent changes in direction of control signal increases stress on the prime mover, and can lead to premature request for unit maintenance. Table 6.4 gives a count of reversals over the observed hour for both techniques and the load in each area. From the numbers it can be easily seen that NERC compliant MPC produces as much as 57\% less unit reversals then the MPLFC controller without additional logic.

Table 6.4: Number of unit reversals

\begin{tabular}{|c|c|c|c|}
\hline & AREA 1 & AREA 2 & AREA 3 \\
\hline LOAD & 871 & 856 & 899 \\
\hline MPLFC & 657 & 702 & 588 \\
\hline NERC MPC & 401 & 300 & 294 \\
\hline $\begin{array}{c}\text { Reduction in } \\
\text { unit reversals [ \% ] }\end{array}$ & $39 \%$ & $57 \%$ & $49 \%$ \\
\hline
\end{tabular}

Both $L_{1}$ norm and the reversal count indicate that implementation of additional logic in the MPC control algorithm considerably reduces excessive unit maneuvering and reversals, and thus significantly decreases wear and tear of the generating units, increases the regular unit maintenance intervals and helps lower associated costs. 


\section{Chapter 7}

\section{Conclusion}

Load Frequency Control design is a very interesting research topic, and it has become even more interesting after the deregulation. In the first part of the thesis, a Model Predictive Control based controller design for the Load Frequency Control problem in an interconnected power system is proposed. Control inputs are calculated in every sampling interval as an optimal control problem solution, penalizing deviation of a model based prediction of the future system behavior from the desired reference trajectory.

The proposed controller is implemented in a completely decentralized fashion, using Area Control Error signal as the only input. A model of a three-area nine-generator system is chosen to present the effectiveness of the Model Predictive LFC controller. The control actions are calculated based on a step response model of the system, with the objective to minimize the effects of uncontrolled changes in area's native load and area's interconnections with the neighboring areas. These effects are treated in control algorithm as unmeasured disturbances and taken into calculations through the error between the measured system output and its prediction.

Simulation results for several scenarios, including normal system operation, large load disturbance in all areas, and loss of a generating unit, have shown a good performance of the proposed MPLFC controller. For all considered cases, the control actions are taken effectively and in timely manner. Furthermore, a comparison with performance of a GALMI tuned PI controllers showed advantages of the proposed control design, especially for the case when significant rate limiter nonlinearities were imposed on the system. 
Quality of load frequency control performance is assessed through the NERC's control performance standards CPS1 and CPS2. All control areas in an interconnected operation are required to report their compliance with the standards on a monthly basis, and those areas with compliance below designated levels are being penalized. In order to assure good control area compliance with CPS1 and CPS2 and avoid penalties, an additional control logic to the MPC design has been proposed in the second part of the thesis. The controller uses updated CPS1 and CPS2 levels of compliance together with the ACE signal as the inputs, with all these signals available at the area control center, thus achieving decentralized control scheme.

The added control logic works in such a way that the control actions are taken only when necessary, i.e. when the compliance is low and close to violation of the NERC's standards. In such a case, the controller will produce a signal to timely adjust the generation and improve area compliance. However, when the compliance is good, the controller will not produce changes in governor set-points avoiding unnecessary maneuvering of the generating units.

The effectiveness of the proposed NERC compliant control scheme is illustrated by using a model of a test system that consists of three control areas with multiple generation and distribution companies. The $L_{1}$ norm of the change in governor set-points and the unit reversals have been chosen to indicate the accumulated unit maneuvering which builds up wear and tear on generating units. The simulation results show that both the $L_{1}$ norm and the reversals are significantly reduced in a case when the proposed algorithm is implemented, compared to those obtained with an MPC controller without CPS compliance and unit maneuvering considerations.

A disadvantage of the proposed MPC control designs is that it requires a complex optimization procedure in every sampling interval, increasing demand on controller's processing power. However, with further development and price-decrease in microprocessing components, this disadvantage could become less important. Moreover, if enforcement of the constraints on the system is not considered, then the solution of the QP problem in equation (4.19) is given with:

$$
\begin{gathered}
\frac{\partial J}{\partial \Delta U(k \mid k)}=H \cdot \Delta U(k \mid k)+f(k)=0 \quad \Rightarrow \\
\Delta U(k \mid k)=-H^{-1} \cdot f(k)
\end{gathered}
$$


yielding a simple multiplication of two matrices, since matrix $H$ with its inversion can be calculated "off-line" and used in the control algorithm as a constant matrix.

The work in the thesis can be further improved by:

- modeling unmeasured disturbance to minimize the prediction error,

- considering governor deadband nonlinearities in the design of the proposed controllers,

- including economic objectives, such as marginal cost of generating units and price of energy, into the performance index in order to make appropriate control decisions. 


\section{Appendix A}

\section{Publications}

\section{[1] Load Frequency Control Using Model Predictive Control}

Abstract: In this paper a Model Predictive Control (MPC) design is proposed for the LFC problem. The MPC controller is implemented in a completely decentralized fashion, using Area Control Error (ACE) signal as the controller input. To achieve decentralization, interfaces between interconnected power system control areas are treated as disturbances. MPC controllers's performance is tested on a three-area power system with three different load disturbance scenarios. Simulation results are presented and compared with those obtained using a robust $H_{\infty}$ controller.

Reference: A. Hasanović, N. Atić, D. Rerkpreedapong, and A. Feliachi, "Load Frequency Control Using Model Predictive Control," Proc. of the 34th North American Power Symposium, Phoenix, AZ, pp. 370-374, October 2002.

\section{[2] Economy Oriented Model Predictive Load Frequency Control}

Abstract: In this paper, Model Predictive Control (MPC) scheme is used to develop the proposed load frequency controller. In each sampling interval, an optimization procedure is performed to calculate optimal control actions. In addition, it has the ability to incorporate economic objectives as part of control requirements. Here, it applies the wedge control philosophy to minimize unit maneuvering and reversals, which affect load frequency control (LFC) costs. The proposed methodology is tested with a three-area power system. Simulation results show that the proposed LFC successfully 
complies with NERC's control performance standards, and also achieves the economic objective.

Reference: D. Rerkpreedapong, N. Atić, and A. Feliachi, "Economy Oriented Model Predictive Load Frequency Control," Proc. of Large Engineering Systems Conference on Power Engineering, Montreal, Canada, pp 12-16, May 2003.

[3] NERC Compliant Decentralized Load Frequency Control Design Using Model Predictive Control

Abstract: This paper presents a decentralized Model Predictive Control (MPC) design for the Load Frequency Control (LFC) problem. The proposed algorithm has two objectives, (1) to assure compliance with control performance standards CPS1 and CPS2 set by NERC, and (2) to reduce wear and tear of generating units. A nonlinear simulation of a test system with multiple generation and distribution companies including regulation and load following services is performed to illustrate the proposed control scheme.

Reference: N. Atić, D. Rerkpreedapong, A. Hasanović, and A. Feliachi, "NERC Compliant Decentralized Load Frequency Control Design Using Model Predictive Control," Proc. of IEEE Power Engineering Society General Meeting, Toronto, Canada, July 2003.

[4] Model Predictive Control Design For Load Frequency Control Problem Abstract: This paper presents a decentralized Model Predictive Control (MPC) design for the Load Frequency Control (LFC) problem. The Area Control Error (ACE) signal was used as the only input to the controller to achieve the decentralized scheme. A part of the ACE signal, which refers to changes in interarea tie-line power flow, and local changes in power demand are treated as an unmeasured disturbance for the controller design. Simulation is performed on a three-area power system model with three different load disturbance scenarios. The results are presented and compared to those obtained using PI controllers.

Reference: N. Atić, and A. Hasanović, "Model Predictive Control Design For Load Frequency Control Problem," 2002 PES Student Prize Paper Award Winner, Award presented at 2003 IEEE PES General Meeting, Toronto, Canada, July 2003. 


\section{Appendix B}

\section{Simulink models and data files}

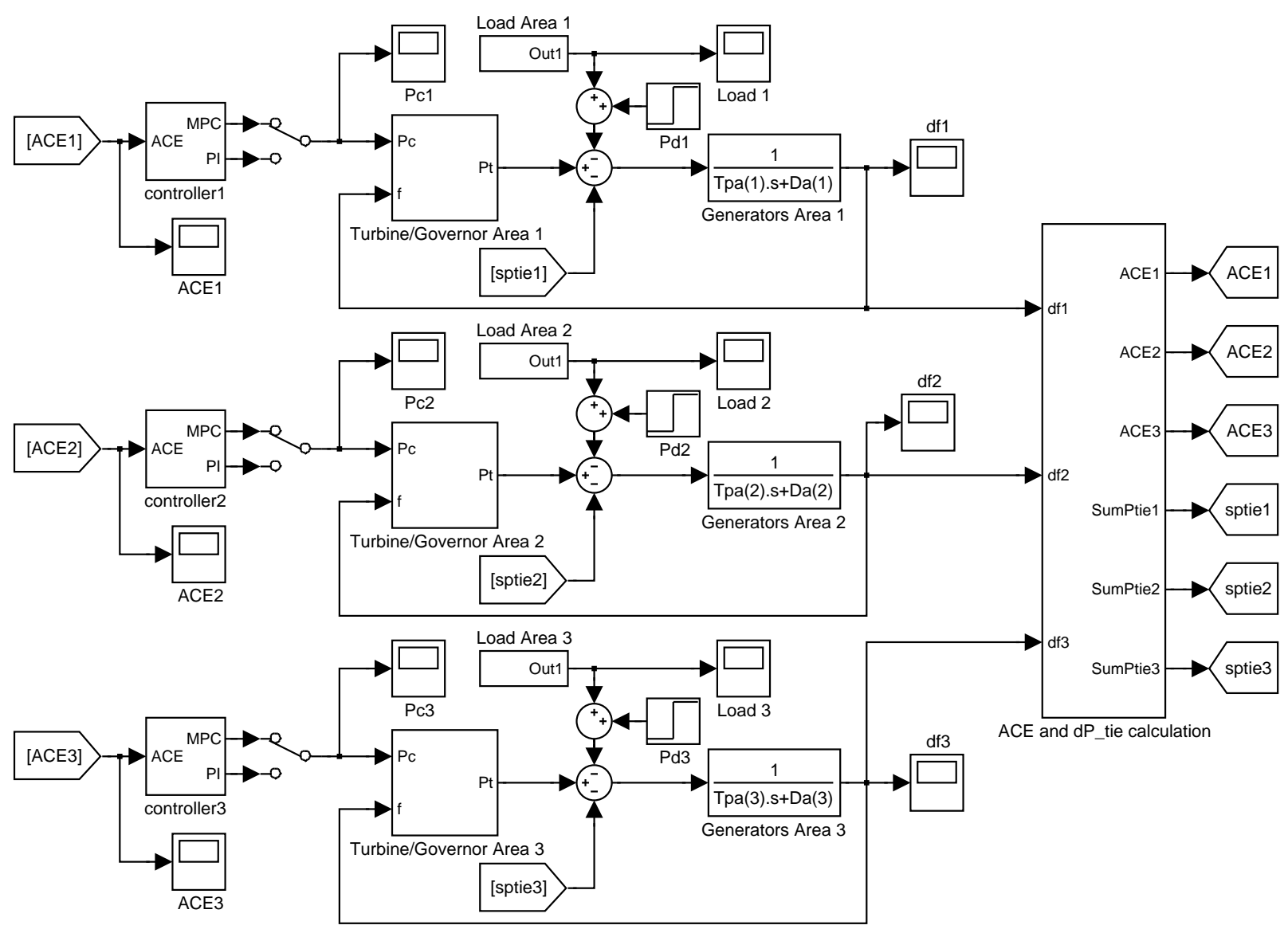

Figure B.1: MATLAB/Simulin model for MPLFC 
Data file for MPLFC case

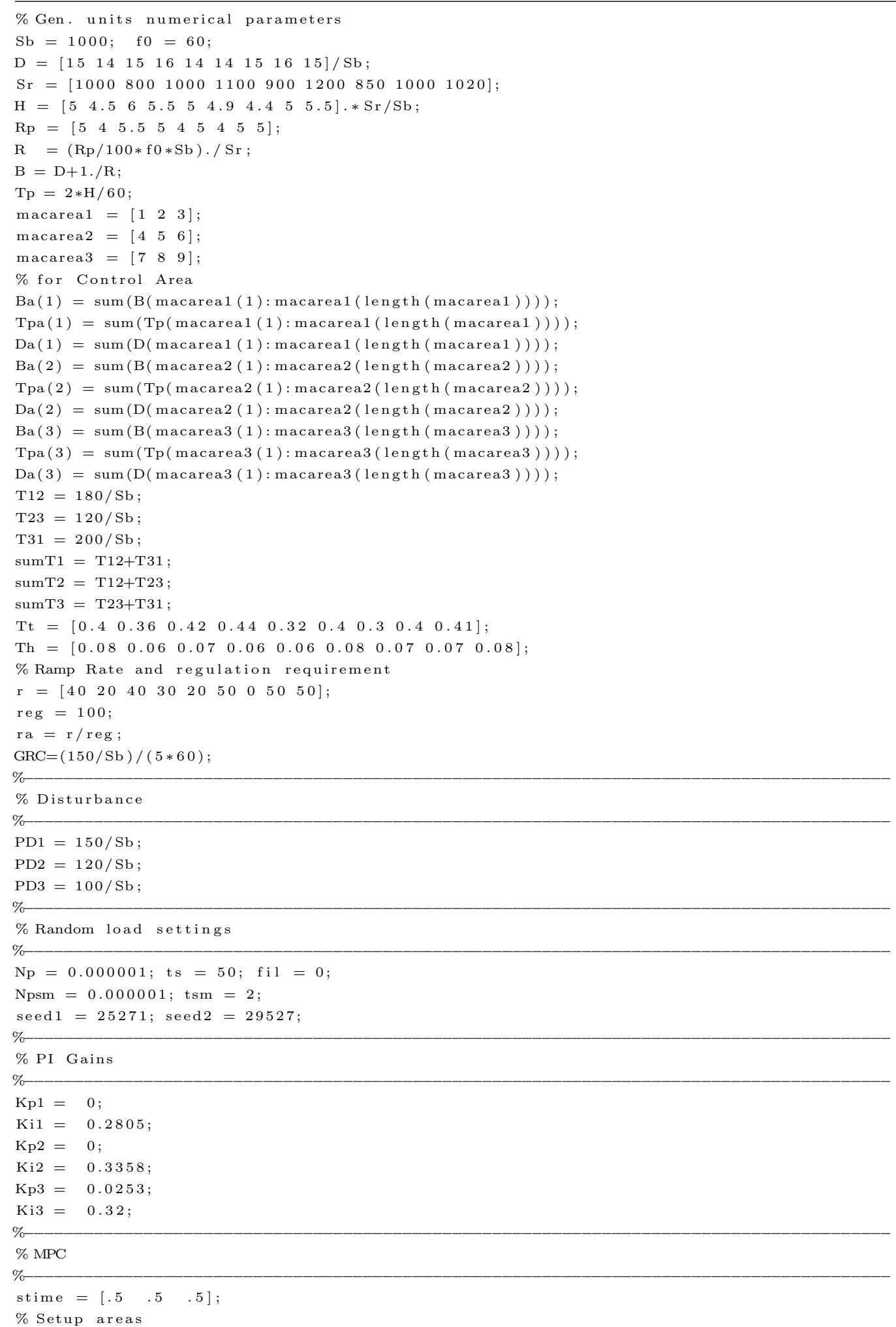




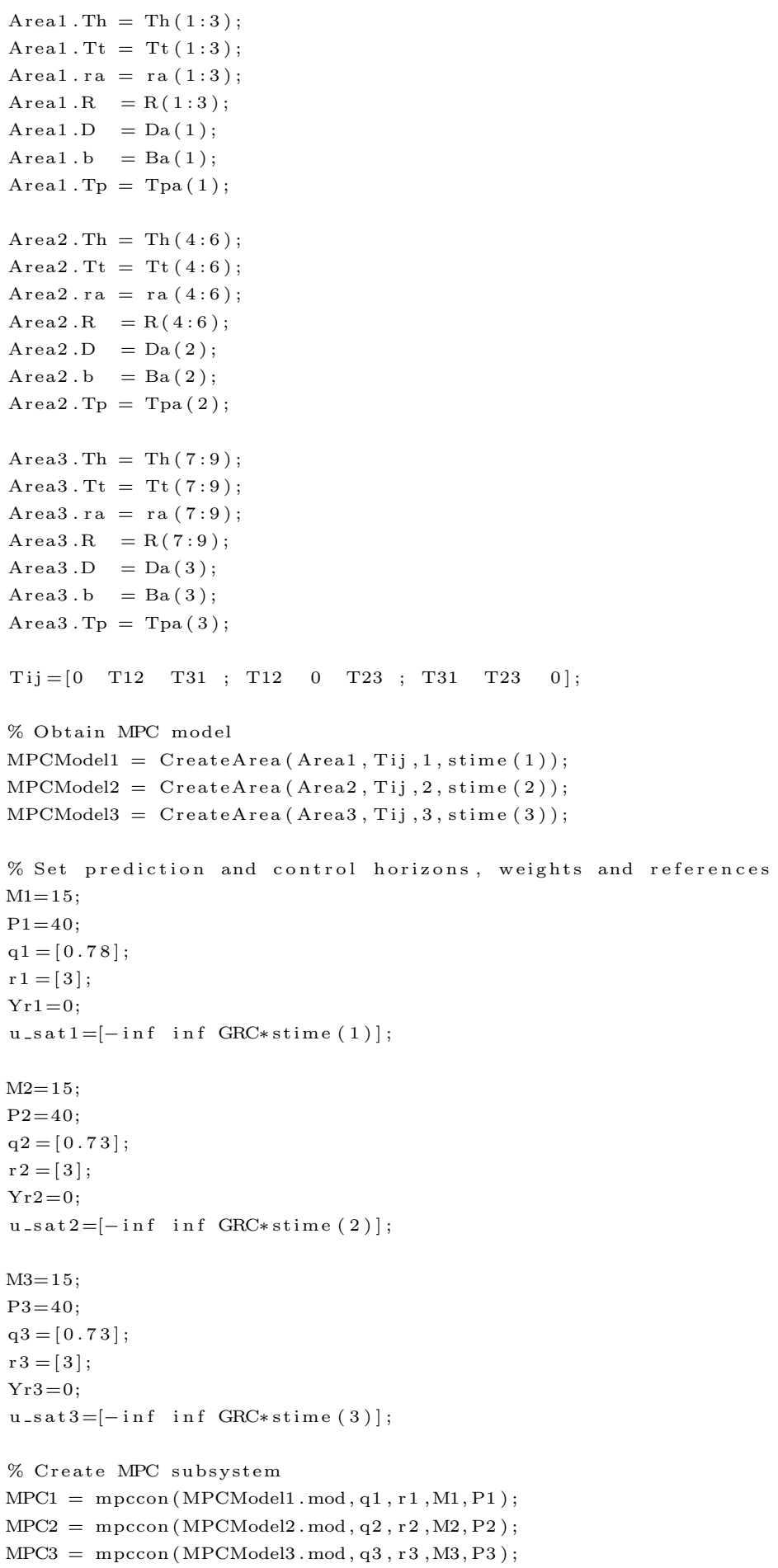


"CreateArea.m" function to obtain area's MPC model

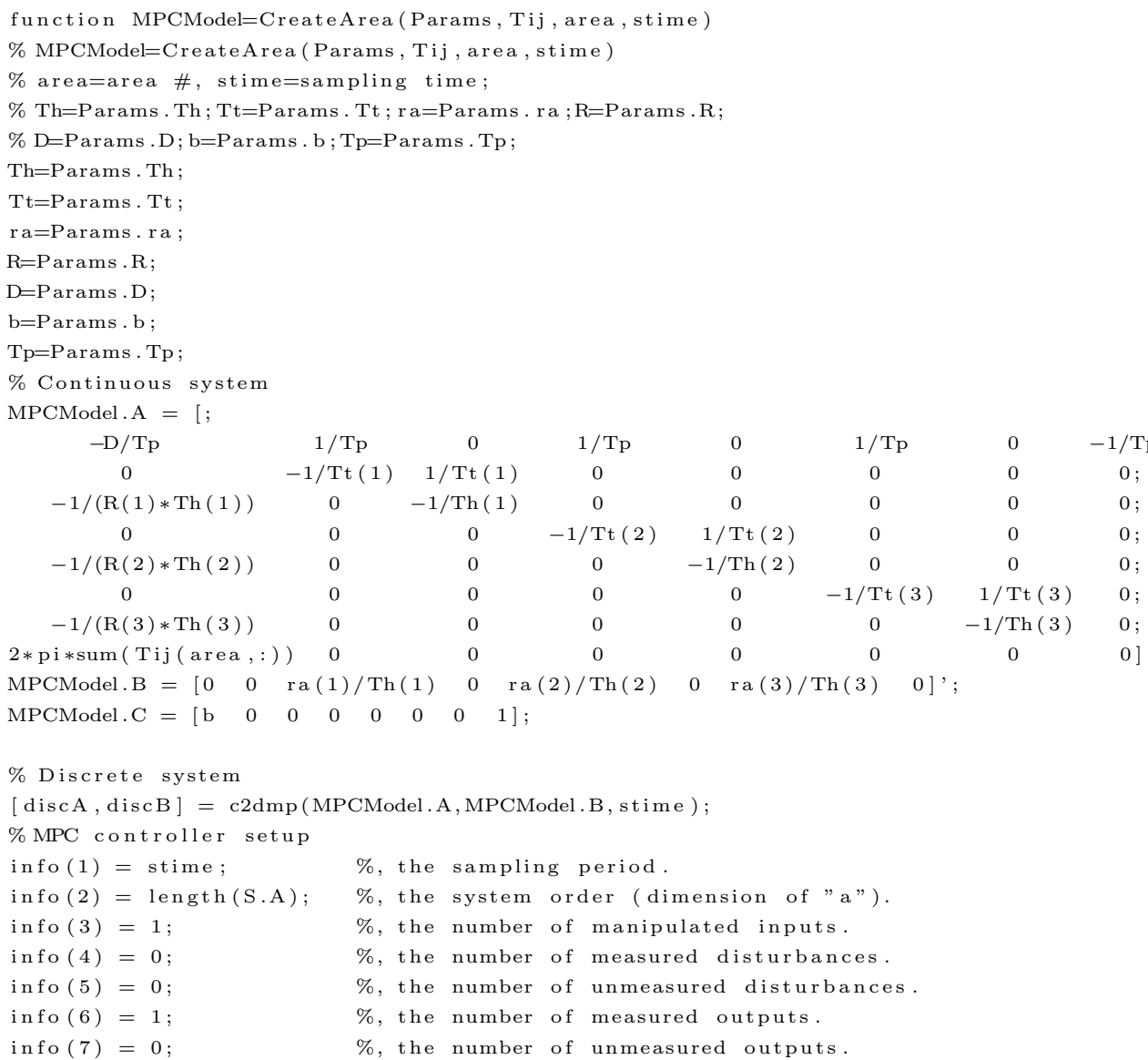




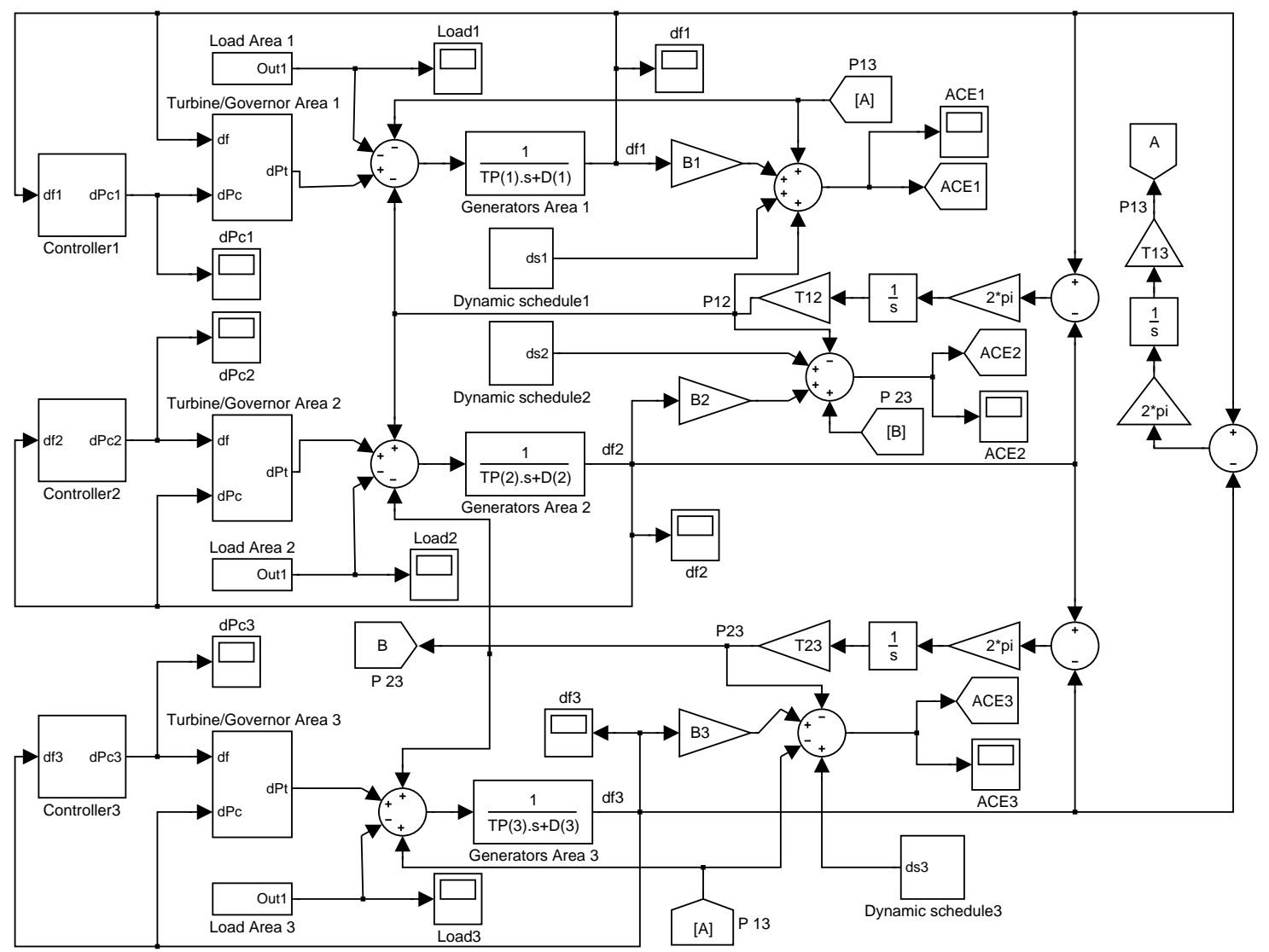

Three area test system model

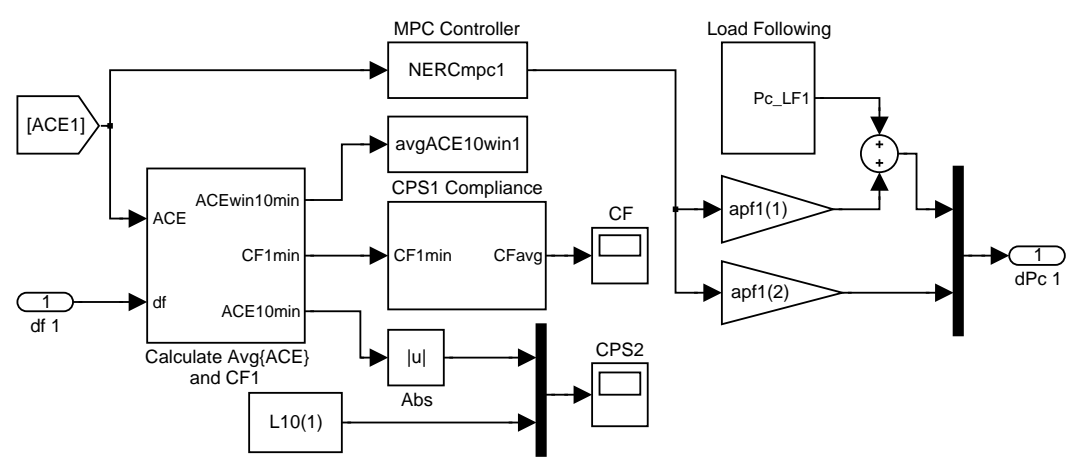

Area 1 NERC compliant MPLFC controller

Figure B.2: MATLAB/Simulin model for NERC compliant MPLFC 
Data file for NERC compliant MPC case

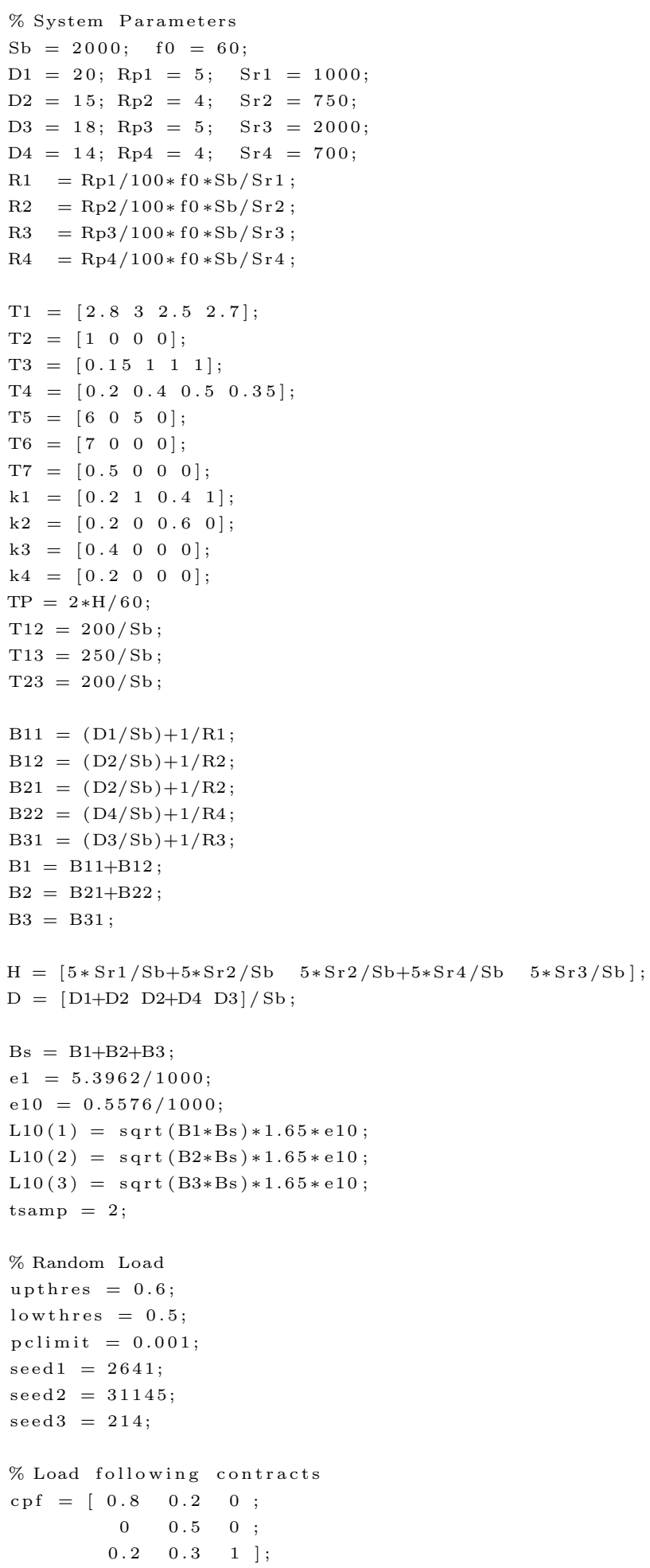

\% Regulating contracts 
$\operatorname{apf} 1=\left[\begin{array}{ll}0.0 & 1.0\end{array}\right] ;$

$\operatorname{apf} 2=\left[\begin{array}{ll}0.5 & 0.5\end{array}\right]$

apf $3=1$;

$\%$ additional parameters

lup $=1.2$

llow $=-1.2$;

rateup $=0.10$

ratelow $=-1.0$

MPCSetup ; 


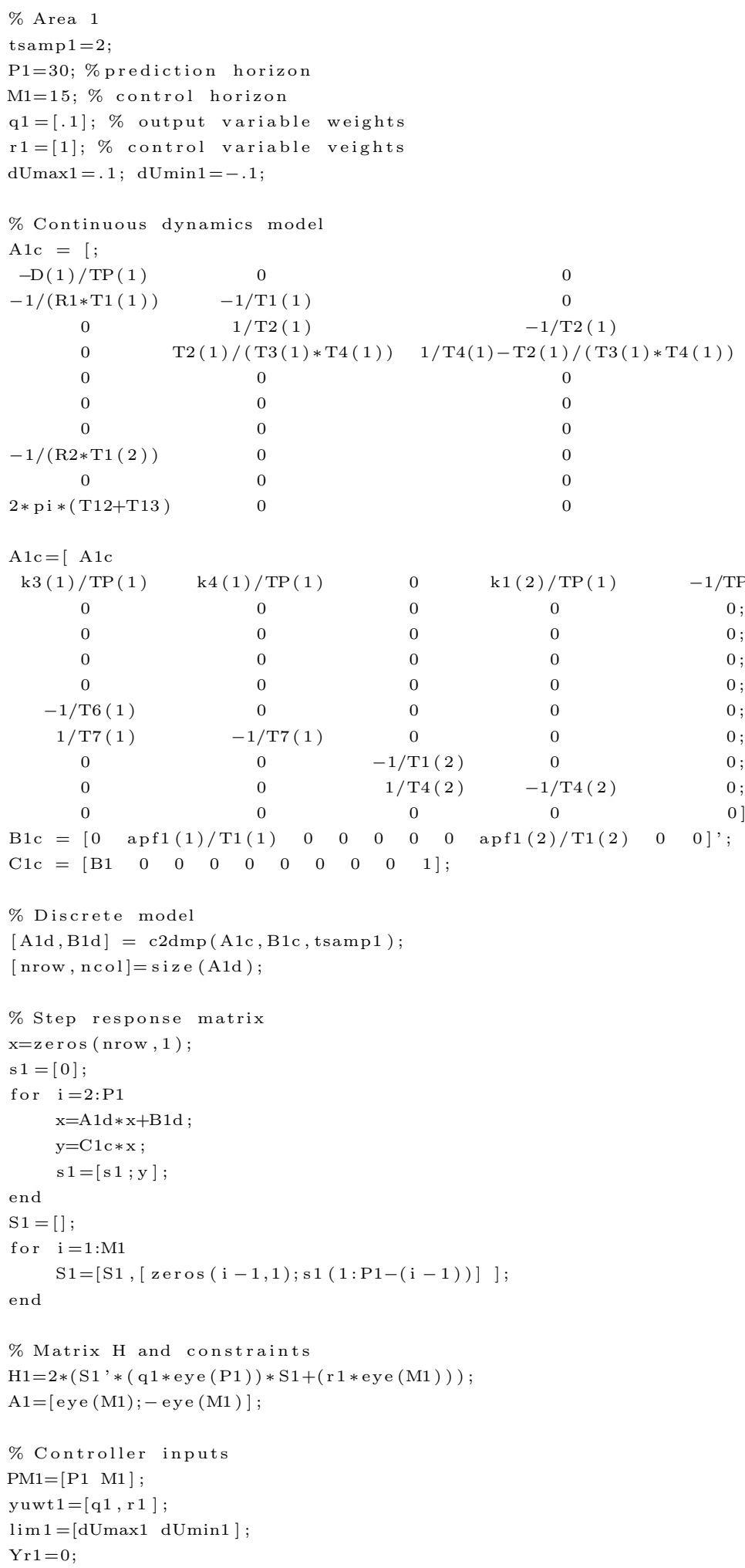

0
0

$2 * \mathrm{pi} *(\mathrm{~T} 12+\mathrm{T} 13)$

$\mathrm{A} 1 \mathrm{c}=[\mathrm{A} 1 \mathrm{c}$

$\mathrm{k} 3(1) / \mathrm{TP}(1)$

$\mathrm{B} 1 \mathrm{c}=\left[\begin{array}{llllllllll}0 & \operatorname{apf} 1(1) / \mathrm{T} 1(1) & 0 & 0 & 0 & 0 & 0 & \operatorname{apf} 1(2) / \mathrm{T} 1(2) & 0 & 0\end{array}\right]^{\prime} ;$

$\mathrm{C} 1 \mathrm{c}=\left[\begin{array}{llllllllll}\mathrm{B} 1 & 0 & 0 & 0 & 0 & 0 & 0 & 0 & 0 & 1\end{array}\right] ;$

$\%$ Discrete model

$[\mathrm{A} 1 \mathrm{~d}, \mathrm{~B} 1 \mathrm{~d}]=\mathrm{c} 2 \mathrm{dmp}(\mathrm{A} 1 \mathrm{c}, \mathrm{B} 1 \mathrm{c}, \mathrm{tsamp} 1)$

$[$ nrow, ncol] $=\operatorname{size}(\mathrm{A} 1 \mathrm{~d})$;

\% Step response matrix

$\mathrm{x}=\mathrm{zeros}($ nrow, 1$)$;

$\mathrm{s} 1=[0]$;

for $\mathrm{i}=2: \mathrm{P} 1$

$\mathrm{x}=\mathrm{A} 1 \mathrm{~d} * \mathrm{x}+\mathrm{B} 1 \mathrm{~d}$;

$\mathrm{y}=\mathrm{C} 1 \mathrm{c} * \mathrm{x}$;

$\mathrm{s} 1=[\mathrm{s} 1 ; \mathrm{y}]$;

end

$\mathrm{S} 1=[]$;

for $\mathrm{i}=1: \mathrm{M} 1$ $\mathrm{S} 1=[\mathrm{S} 1,[\operatorname{zeros}(\mathrm{i}-1,1) ; \mathrm{S} 1(1: \mathrm{P} 1-(\mathrm{i}-1))]]$;

end

\% Matrix $\mathrm{H}$ and constraints

$\mathrm{H} 1=2 *\left(\mathrm{~S} 1{ }^{\prime} *(\mathrm{q} 1 * \operatorname{eye}(\mathrm{P} 1)) * \mathrm{~S} 1+(\mathrm{r} 1 *\right.$ eye $\left.(\mathrm{M} 1))\right) ;$

$\mathrm{A} 1=[$ eye (M1); - eye (M1) ];

\% Controller inputs

$\mathrm{PM} 1=[\mathrm{P} 1 \mathrm{M} 1]$;

yuwt $1=[\mathrm{q} 1, \mathrm{r} 1]$

$\lim 1=[\mathrm{dUmax} 1 \mathrm{dUmin} 1]$;

$\operatorname{Yr} 1=0$;

$\begin{array}{cc}0 & 1 / \mathrm{T} 6(1) \\ 0 & 0\end{array}$

0

0 


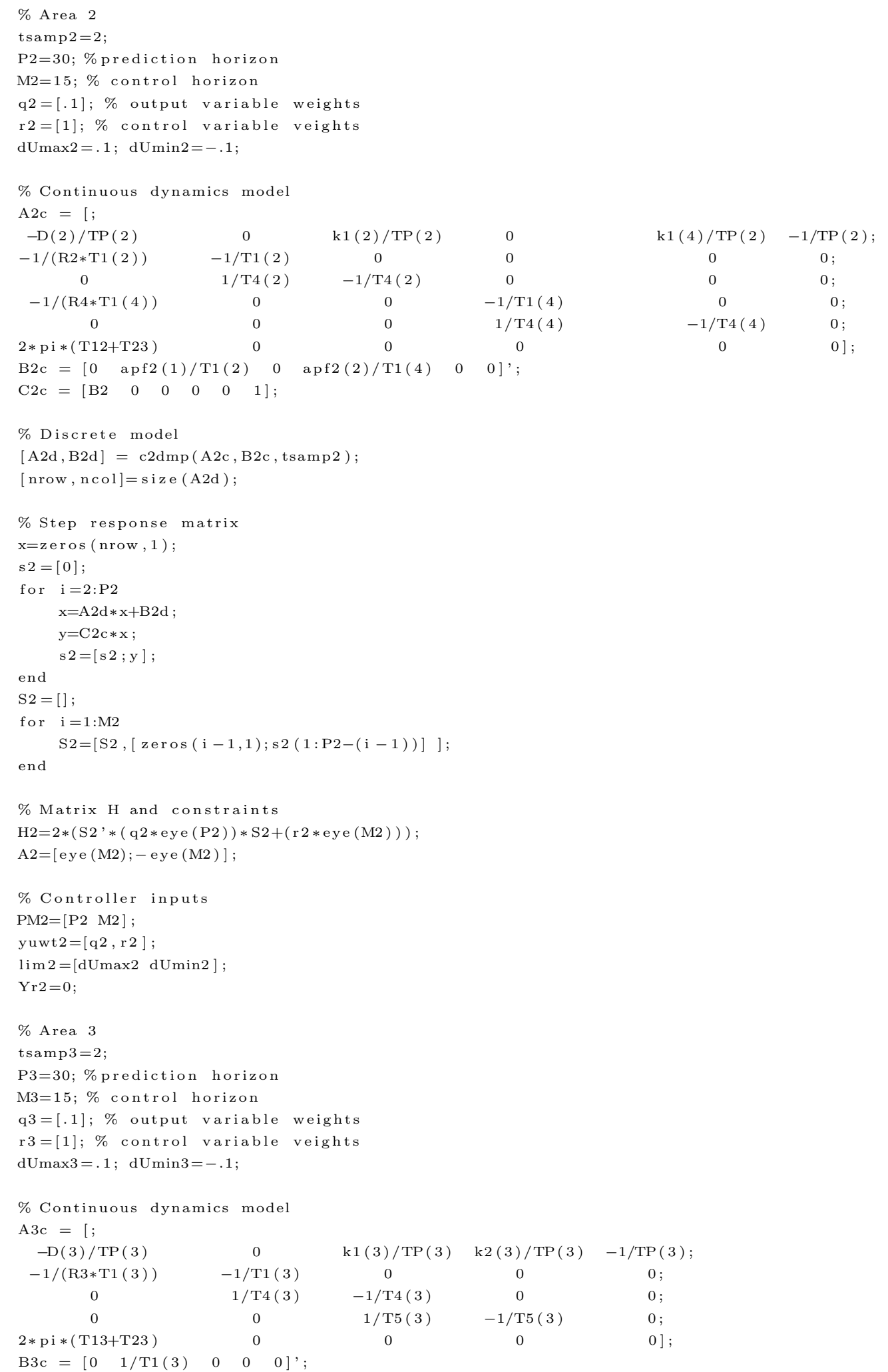




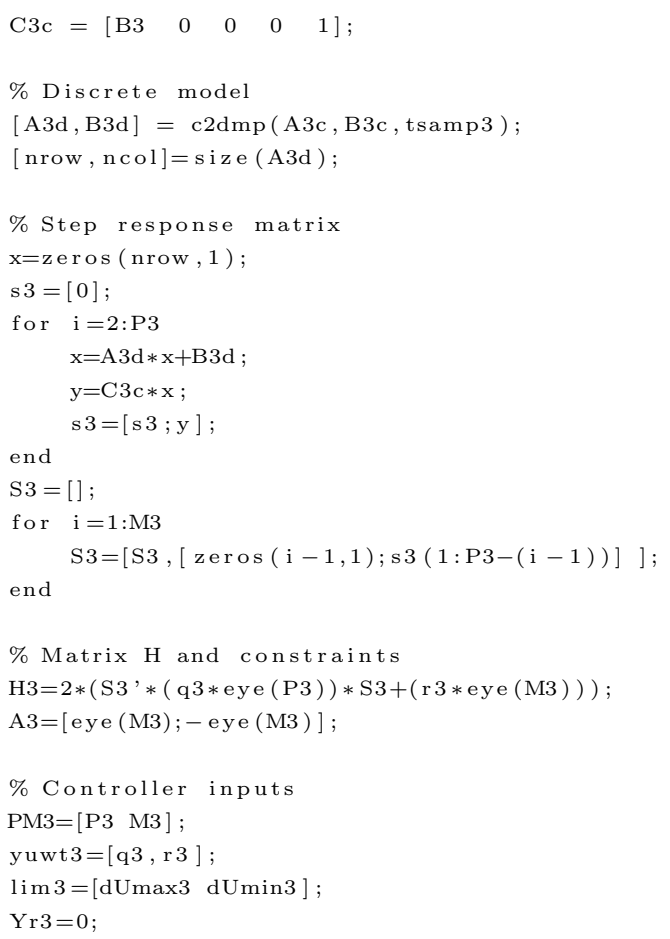


"NERCMPC.m" S-function executed in every sampling interval

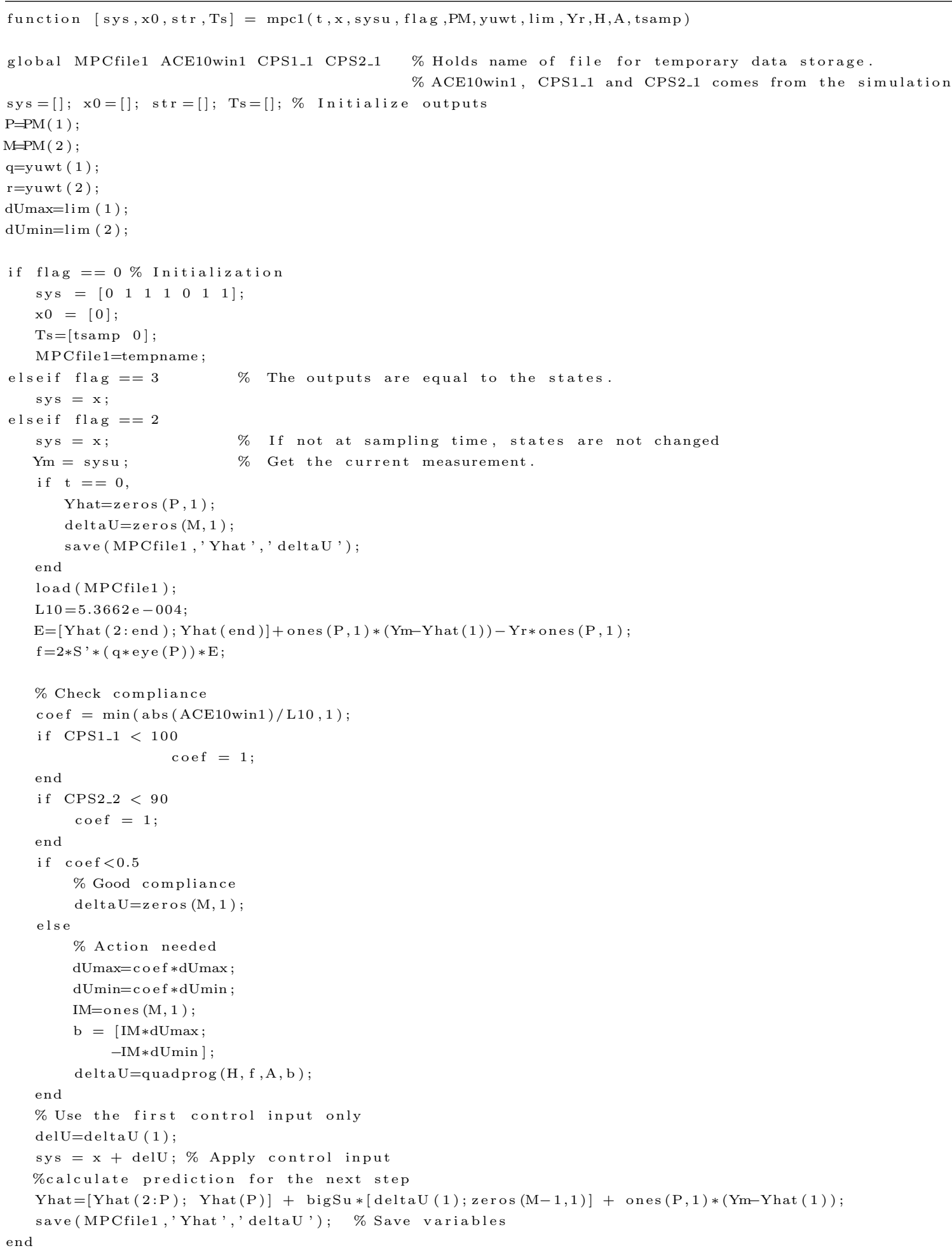




\section{References}

[1] Electric Power Research Institute (EPRI), "Interconnected Power System Dynamics Tutorial," March 1997.

[2] L.S. VanSlyck, N. Jaleeli, and W.R. Kelley, "A Comprehensive Shakedown of an Automatic Generation Control Process," IEEE Transactions on Power Systems, vol. 4, no. 2, pp. 771-781, May 1989.

[3] N. Jaleeli, L.S. VanSlyck, D.N. Ewart, L.H. Fink, and A.G. Hoffman "Understanding Automatic Generation Control," IEEE Transactions on Power Systems, vol. 7, no. 3, pp. 1106-1122, August 1992.

[4] A. Feliachi, "Optimal Decentralized Load Frequency Control," IEEE Transactions on Power Systems, vol. 2, no. 2, pp. 379-386, May 1987.

[5] N. Jaleeli, and L.S. VanSlyck, "Tie-Line Bias Prioritized Energy Control," IEEE Transactions on Power Systems, vol. 10, no. 1, pp. 51-59, February 1995.

[6] A.M. Stanković, G. Tadmor, and T.A. Sakharuk, "On Robust Control Analysis and Design for Load Frequency Regulation," IEEE Transactions on Power Systems, vol. 13, no. 2, pp. 449-455, May 1998.

[7] D. Rerkpreedapong, A. Hasanović, and A. Feliachi, "Robust Load Frequency Control Using Genetic Algorithms and Linear Matrix Inequalities," IEEE Transactions on Power Systems, vol. 18, no. 2, pp. 855-861, May 2003.

[8] D. Rerkpreedapong,, "Novel Control Design and Strategy for Load Frequency Control in Restructured Power Systems," PhD Dissertation, West Virginia University, Morgantown, WV, 2003.

[9] D. Rerkpreedapong, and A. Feliachi, "Fuzzy Rule Based Load Frequency Control in Compliance with NERC's Standards," Proceedings of the IEEE Power Engineering Society Summer Meeting, Chicago, IL, July 2002. 
[10] D. Rerkpreedapong, and A. Feliachi, "PI Gain Scheduler for Load Frequency Control Using Spline Techniques," Proceedings of the IEEE Southeastern Symposium on System Theory, Morgantown, WV, March 2003.

[11] K. Schoder, A. Hasanović, A. Feliachi and A. Hasanović, "PAT: A Power Analysis Toolbox for MATLAB/Simulink," IEEE Transactions on Power Systems, vol. 18, no. 1, pp. 42-47, February 2003.

[12] V. Donde, M.A. Pai, and I.A. Hiskens, "Simulation and Optimization in an AGC System after Deregulation," IEEE Transactions on Power Systems, vol. 16, no. 3, pp. 481-489, August 2001.

[13] N. Jaleeli, and L.S. VanSlyck, "NERC's New Control Performance Standards," IEEE Transactions on Power Systems, vol. 14, no. 3, pp. 1092-1099, August 1999.

[14] G. Gross, and J.W. Lee, "Analysis of Load Frequency Control Performance Assessment Criteria," IEEE Transactions on Power Systems, vol. 16, no. 3, pp. 520-525, August 2001.

[15] North American Electric Reliability Council (NERC), Resources Subcommittee CPS Reports . Available Online: http://www.nerc.com/ filez/cpc.html

[16] J.B. Rawlings, "Tutorial Overview of Model Predictive Control," IEEE Control Systems Magazine, vol. 20, issue 3, pp. 38-52, June 2000.

[17] S.J. Qin, and T.A. Badgwell, "An Overview of Industrial Model Predictive Control Technology," Proceedings of Fifth Chemical Process Control Conference, pp. 232-256, 1997. http://www.che.utexas.edu/ qin/cpcv/cpcv14.html

[18] S.J. Qin, and T.A. Badgwell, "An Overview of Nonlinear Model Predictive Control Applications," Nonlinear Predictive Control, pp. 369-393, Birkhäuser, 1999.

[19] D. Jia, and B.H. Krogh, "Distributed Model Predictive Control, " Proceedings of the American Control Conference, pp. 2767-2772, June 2001.

[20] E. Camponogara, D. Jia, B.H. Krogh, and S. Talukdar, "Distributed Model Predictive Control," IEEE Control Systems Magazine, pp. 44-52, February 2002.

[21] North American Reliability Council (NERC), "Performance Standards Reference Document," version 2, pp. PS1-19, November 2002.

[22] E.F. Camacho, C. Bordons, "Model Predictive Control," Springer-Verlag, 1999.

[23] M. Morari, J.H. Lee, C.E. Garcia and D.M. Prett, "Model Predictive Control", to be published by Prentice Hall, 2003. 
[24] S. Boyd, L. Vanderberghe, "Convex Optimization", to be published by Cambridge University Press, 2003.

[25] Optimization Toolbox, Optimization Toolbox User's Guide, The Mathworks, Inc., 2001.

[26] P. Kundur, "Power System Stability and Control", McGraw-Hill, Inc., 1994.

[27] M. Morari, and N.L. Ricker, "Model Predictive Control Toolbox User's Guide", The Mathworks, Inc., 1998.

[28] J. Kumar, K.H. Ng, and G. Sheblé, "AGC Simulator for Price-Based Operation - Part I: A Model," IEEE Transactions on Power Systems, vol. 12, no. 2, pp. 527-532, May 1997.

[29] J. Kumar, K.H. Ng, and G. Sheblé, "AGC Simulator for Price-Based Operation - Part II: Case Study Results," IEEE Transactions on Power Systems, vol. 12, no. 2, pp. 533-538, May 1997.

[30] E. Hirst, and B. Kirby, "Ancillary-service details: regulation, load following, and generator response," Oak Ridge National Laboratory, Oak Ridge, TN, Tech. Rep. ORNL/CON-433, September 1996. 